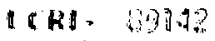

PRIPRISI

MASTER

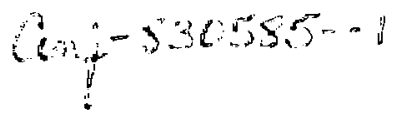

\title{
MULTIGAMMA-RAY CALIBRATION SOURCES
}

\author{
R. A. Meyer and T. N. Massey \\ Nuclear Chemistry Division \\ Lawrence Livermore National Laboratory \\ Livermore, CA 94550
}

This paper was prepared for submittal to

ICRM Seminar on Applied Radionuclide Metrology,

Gee1, Belgium, 5/16-17/83

May 1983

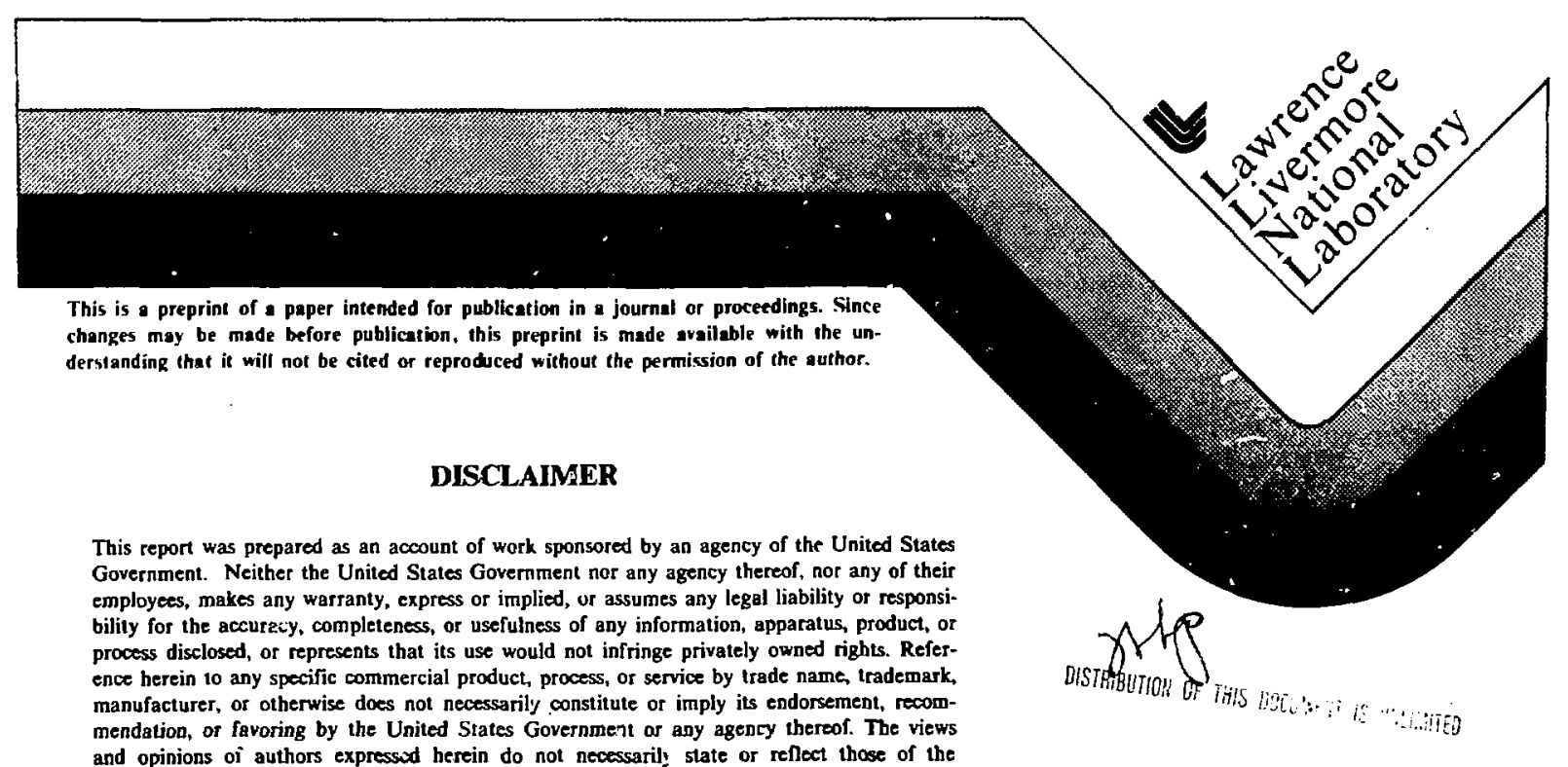

and opinions oi authors expressud herein do not necessarily state or reflect those of the United States Government or any agency thereor. 


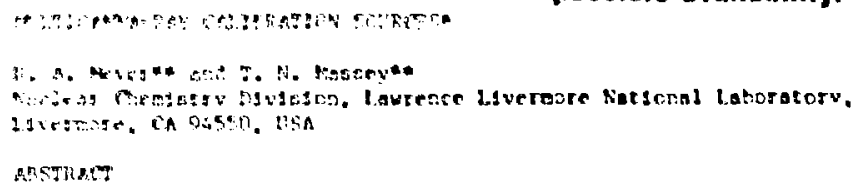

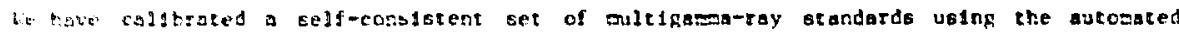

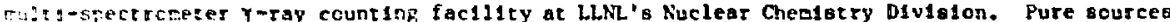
of icne-lived activity were produced by cass separacion and/or chealcal purlfication. The surces weze counted individually and in combination on several different calibrated spectrogeitr systess. These systers ut1l1ze varlous detectors ranginf frcs sesll $(x-r a y)$ detectorb to arge volume hlgh-purity Ge detectors. Th1s has allowed the use of the cost ldeal 1nitgidual Cetector-efficletr., characteristics for the determination of the relative y-ray intensitles. Precise enercy reasurecents, reported earller (Meyer. 1976) have been perforded by an Independent sethod. Soth the energy and y-ray-eoission probabilities we detercine compare weld with 1rdependently established values such as the secent ICRM Intercomparison of $152 \mathrm{Eu}$. his discuss our investikations alced at resolving the ehape of the efficlency response function us to $10 \mathrm{MeV}$ for large volugf $\mathrm{Ge}(\mathrm{Ll})$ and high-purity Ge detectors. Recent results on the -rav-enlssion probabllities per decay for ${ }^{149} \mathrm{Gd}$ and $168 \mathrm{Tm}$ wultigana-ray sources are discussEd. For $168 \mathrm{Tm}$, we deduce a $0.01 \% \mathrm{~B}^{-}$branch to the $87.73-k e v$ level in $168 \mathrm{Yb}$ rather than the orevious value shich was a facto: of 200 greater. In addition, we describe current cooperative efforts almed at establishing a consistent set of data for short-lived fission products. Included are recent measurements on the bromine flssion products with r rays up to 7 MeV.

\section{INTRODUCTION}

The ideal calibrafion source for a Y-ray spectrometer is a single, long-lived radicactive nuclide possessing a large number of equally intense $r$ rays at evenly-spaced energy intervals. Surh a source enables repeated energy and efficlency callbration measurements to be mede on automated multispectrometer analvitcal bystems. In research, the geometry of the source with respect to the detector and attenuating materials can vary widely within a single expe iment, necessitating several separate callbration measurements. Although no 1 deal calibrat 1 sn source has been found, several long-lived radloactive Isotopes have proven useful coningales. In an effort to develop a self-consigtent get of multigama-ray callbration ourceg we have wade neasurements of prectse $\gamma$-ray energy and emission probability values, and have characterized the efflclency of Ge(L1) and high-nurity Ge detectors up to $10 \mathrm{MeV}$. Our InItial results have appeared in unpublished tables (Meyer, 1978A) and preliminary reports (Meyer. 1976; Heyer. 197AB; Lin 1980). Our values are in good agreement with those of other 1nvestigators (Debertin, 1980; Yosh1zawa, 1980A; Yoshizawa, 1980B). Here we review the procedures we have used to determine these values and give our present values. In addition, we c1te some recent measurements of shorter-lived activities present in fissiol products which emit high-energy r ravi.

It 15 1mportant to note that the $Y-r a y-e m i s s i o n$ probabilities we preaent in this report are the result of neasurement of each source on several different apectrometers witi differeit effictency characteristics. In addition, intersource calibration was performed. Sources of established ultigama-ray standards such as $152 \mathrm{Eu}$ also were counted simultaneously with, for example, ${ }^{168} \mathrm{Tm}$. In this way any local variation in the detector efficiency or counting conditions could be checked.

\section{SPECTROSCOPY TECHNIOUES}

Most sources used in the measureqents were both chemlcally purifled and mass separated. For some nuclides, such as $152 \mathrm{Eu}$, sources were prepared by two cycles of chemical purification followed by mass separation. SpectraI data were accumulated with several spectrometer systews employing a va-foty of detectors and standard pulse-processing electrontc components. The spectra analyses were nerformed using the code GAMANAL by Gunnink and coworkers (Gunnink, 1971/1972; Gunnink, 1980; Gunnink 1983). Th1s code divides spectrum analysis into two parts: f1rst, the reduction of the spectral features into understandable entities such as peak energles and areas, and secondly, the quentitative interpretation of these iters as disintegracion rates or atoms of specific nuclides at a specified tive.

*Th1s work was performed under the auspices of the U. S. Department of Energy by the Lawrence Livernore Natlonal Laboratory under contract No. W-7405-Eng-48.

**Addriss uat11 1 October 1983: IKP KFA-Jül1ch Gmbk, Postfach 1913, D-5170 Jü11ch-1, West Germany. 


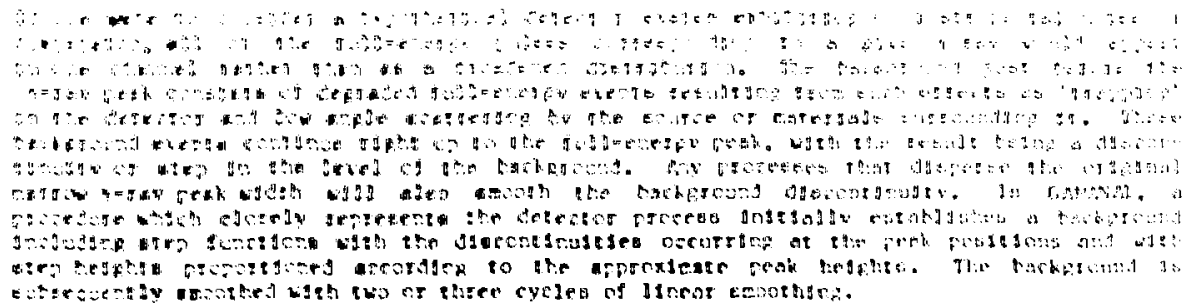

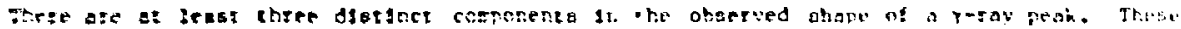

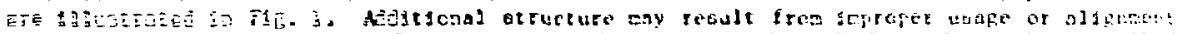
of the eleztcrite erdponents of the eystem. The eajor portton of the peak car be descrlbet by a cosplan fuctelen. However, accurate data analysis requires that the "ehort-ters" ialites. in particuler, not be ipnored. The "long-tero" talling cav he lopotzont in the enalysts c! scse ccrplex mitiplets. Crherwise, It can frequently be treated as nart of the

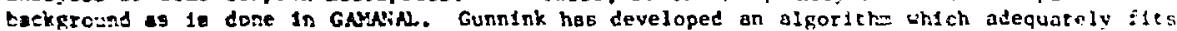
the osserved feak shepes. Techniques have been devised (Gunnink, 1975) whereby all of the peak shape parazeters can be fixed fros fitting two widely separated peaks in a spectrus.

The sifulteneous fitting of several peaks in a gultiplet is generally accomplished by some 1terative sethod. For exemple, GAMANA linearizes the fit equations by using a Taylor's expansion about the trial solution and then uses a Newton-Raphson or Gauss iterative technique. Very coaplicated $\gamma$-ray unitiplets can be unfolded ueing this approach (Gunolnk 1975).

Ar exacple of the spectral analysis can come frod our recent 1nvestigation of 93-day 16RT. In F1gs. 2 and 3 ve show the GAMANal f1t to the 1ntense 79- and $184-k e v$ ray peaks. These f1gures 1llustrate one other feature of tine LLN automated systems. When a channel location exceeds one alllion events, the channel overflow ts registered in the cortrol computer and identifled with the particular spectrum. These channels are liter corrected when the spectra are analyzed on larger computers thereby extending the statistics by which an individual pea* can be measured. Figures 4 and 5 1llustrate the sensitivity with which doublet peaks can be resolved. In all the measurements presented here, the photopeak shape paraneters were f1t individually to each spectrum.

\section{EFFICIENCY DETERMINATION}

If $G e$ (L1) detectors are to be used for quant1tat1ve measurements, they must be cal1brated using appropriate oources. The counting efficiency at any particular $\gamma$-ray energy is dependent on number of factors. Most of these are assoclated with the photon 1nteraction process within the detector, the source-detector geometry, or with r-ray attenuations within the scurce or from surrounding materlals. If the samples to be snalyzed all hare the sane size, shape, set of radiuactive components, and activity level, then $1 \mathrm{t}$ is possible to carry out a specific calibration for this sample type such that $y$-ray peak areas can be directly converced to the desired units. This condition does not generally prevall in our case. As a conseouence, Gunnink has developed a nore flexible approach in which he separates the overall efficlency into two components as follows: efficiency $=\varepsilon \times G$, where $\varepsilon=1$ intrinsic efficlency, and $G$ - a geometry factor 1ncluding attenuation factors. This scheme requizes only one efficlency curve, which can be uaed for all samples withaut regard for their shape, size, activity level, or distance from the detector. A rather elaborate wodel has been developed to compute the geomerry factor and has been discussed by Gunnink (1976). We have explored the question of how well we can flt a region of the efficlency cuive above 300 keV but belcis $2000 \mathrm{keV}$. This was done as part of our studies of ${ }^{134} \mathrm{Cg}$ decay where special attention was given to the measurement of the relative Y-ray em1ssion prababilities as precisely as possible. The uncertainties shown for the relative emission probabilities in tho tables are a result of the measurements described by Van Bfse (1975).

One might ask if there $1 \mathrm{~s}$ a way one can test the relative efficiency curves that are in use today by using sources that have an Inherent accuracy better than the known detector efficlencles? The answer is a qualifled yes. F1rst, we wish to recall some pertinent nuclear decay festures. If the Rround-gtate op!n of a parent nucleus differs greatly from the groundstate spin of the decay product nuclaus, then any decay branch occurring directly between the ground states is negligibly smaii. In this case, the decay may cascade through several levels where maximum angular momentum charge occurs. In the 1deal case, a $Y$-ray cascade will result with several $Y$ rays of wth equal eqlssion probab1lictes but different energy. We have encountered at least three cases, the decays of $93_{\mathrm{p}}^{\mathrm{m}}$, $48 \mathrm{~V}$, end $48 \mathrm{Sc}$. In the decay of these three nucle1, their low nuclear charge 2 does rot allow slgniflcant electron conversion to occur. Our measurements can easily reproduce equal r-roy emission probabilitier for the $Y$ rays from these decays to within 2 percent. However, to reach the statist1cal 


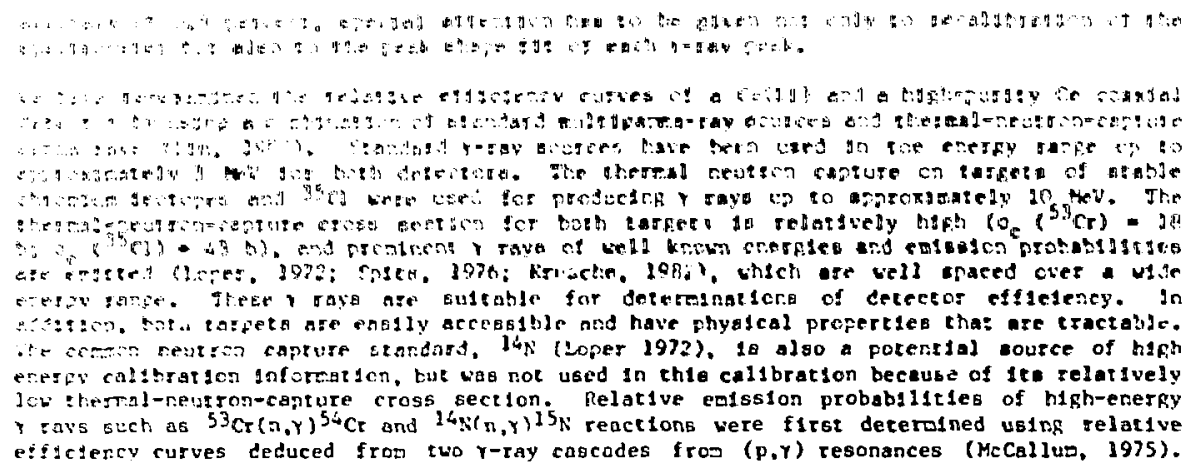

The lack of consistent. reliable efflctency standards at high energy has caused asny ceasurecerss of thertal-capture-ga=a-ray ealssion probabilities to be in error by core than 16. With expericental improvecents the uncertainty of relative ealsalon probabilities for $y$ ravs in the $35 \mathrm{Cl}(\mathrm{n}, \mathrm{y}) 36 \mathrm{Cl}$ reaction have been reduced to a value vhteh is comparable to those for the $Y$ rays fron the $14 \mathrm{~N}(n, \gamma)^{1 S_{N}}$ reartion $(-5 \%)$. For our vork, we have comblned both standard pultigatsa-ray sources and capture r-ray sources to deteralne the relative detector effjclency curve by norwalizing strong low-energy $Y$ rays in the capture $Y$-ray sources to the curve cetermined frov radioactive standards. If the y-ray emission probability per decav of the standard $y-r a y$ source is known, the intinstc efficlency of the detector can also be deceralned at ilgh energy.

An external beam of thermal neutrons with a flux of approximately $10^{9} \mathrm{n} \cdot \mathrm{cm}^{-2} \cdot \mathrm{s}^{-1}$ were obtalned from the Livermore Pool-Type Reactor. Targets of natural abundance chromlum metal and $\mathrm{CCl}_{4}$ sealed inside a pyrex tube were placed separately in the neutron beam at a distance of $32 \mathrm{~cm}$ from the leadshielded $\gamma$-ray detector. Liquid-nitrogen-cooled ORTEC coaxial detectors (one Ge(LI) and one hish-purity Ge), hoth with on efficiency of approxicately $13 \%$ and a resolution of approximately $2 \mathrm{keV}$ at $1.332 \mathrm{MeV}$, were placed at an angle of $90^{\circ}$ to the neutron bean. standard nuclear spectroscopy equipment including a Canberra 80 series wultichannel analyzer was used. A standard $\mathrm{Pb} x$-ray absoriver consigting of $\mathrm{Cu}$ and $\mathrm{Cd}$ folls burrounded the detector during the measurements. Extraction of $\gamma$-ray peak areas from the spectral data was done by using the avallable programs in the analyzer.

In Fig. 6 we present the relative efficlency curves for both detectors that result from our work using a combination of standard multiganma-ray sources and capture $\gamma$ rays. The top curve in F1g. 6 is for the high-purity Ge detector while the bottom curve 18 for the Ge(L1) detector. Hoth curves deviate rather rapidly from the seraight ilne extrapolation above 3 :ev on the $10 \mathrm{~g}-1 \mathrm{og}$ graph. At approximately $10 \mathrm{kgV}$, the measured efficiency $1 \mathrm{~s}$ approximately a factor of 2 below the efficlency obtained by a stralght line extrapolation from lower energies. For the energy region between $300 \mathrm{keV}$ ad $3 \mathrm{MeV}$, the curve appears to be a straight 11ne. The dotted lines indicate the linear extrapolations for the purpose of comparisons with the measured relative efficlency curves. Thrsa relative efficieny curves are slatlar in shape to those measured hy McCallum and Coot:e (1975).

Tabie 1 gives the coefficients of $5 \mathrm{th}$ and $6 \mathrm{ch}$ order polynomials obtained $\mathrm{frow}$ an unweighted computer fit to the data points for two differert energy reglons. The polynomiels are in the form of $\ln E_{1}=\sum_{f u l, 6} a_{1}\left(\ln E_{1}\right)^{j-1}$, where $E_{1}$ represents the $\gamma$-ray energy in units of MeV and $a_{j}$ are coefficlents given in Table 1. Both polynomials are plotted as swooth curves 1. Fig. 6 .

When plotted on a senilogarithmic plot, the relative efficlency curve for each detector appears to be lintar from 2 to $10 \mathrm{MeV}$. From the practical point of view, extension of the relative efficiency curve based on a straight line extrapolation on a Bemilogarithmic plot would be a workable method for obtaining an approximate relative efficjency curve at high energy, even without using thermal neutron capture $r$ rays. Since the slope af the curves for these iwo decectors is slightiy different at high energy, it would become more rellable to have at least one independent calibration point at high energy. A possible callbratica

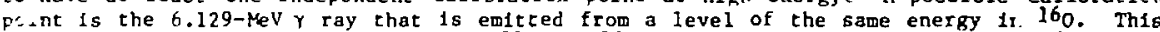
$Y$ ray is emitted following the reaction $13 \mathrm{C}(a, n) 160$. A combination source such as $244 \mathrm{Co}+1{ }^{2} \mathrm{C}$ can be made and the emission rate for the $6.129 \mathrm{MeV} Y$ ray can be measured. Hence, a becondary standard $\gamma$-ray source for establighment of the high-energy portion for borh energy and efficiency calibration is possible. A comparison between our new relative y-ray emission probabilities for $B B_{B r}$ decay which emlt $Y$ rays with energies up to $7000 \mathrm{keV}$, is compared to previous values in Table 2 . 


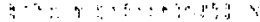

or e g)

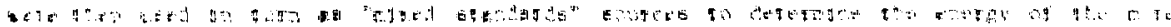

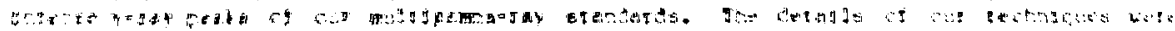

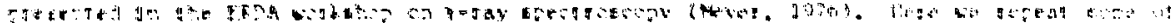

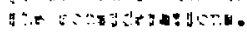

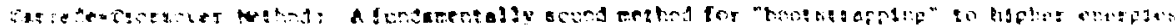

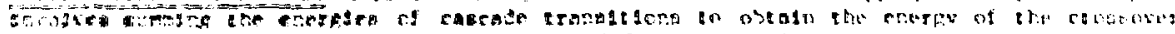

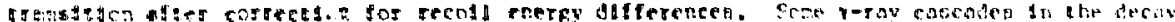

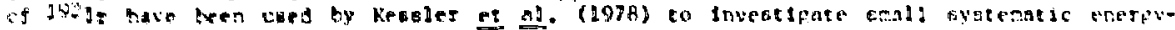

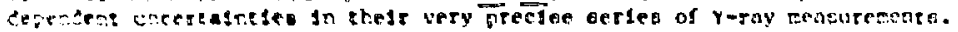

in shets wak Grernuced (1970), le]cer (19)1), sad Gehrke (1979) used the two different sets of cosectes as - bess for sutsiancsally increasing the nucber of roray enerfy standards Eelow $1300 \mathrm{keV}$ ned then extended r-ray energy seandards to 3.5 ply (Greenwood, 1979). The zeasured ene-5y differences were obrained using Ge(I.1) spectroceter techniques. The values ottalied fer energy differences are relatively insensitive to changes in the calibration ererales. Explicit energy differences enable easier future revision in case core accurate pricary stardarcs becose ayallable. These aurhors have also done a gore careful uncertalnty ensivs16 than one finds in tuch of the previous work. They expliciely identifled the systenatic uncerteinty component of the fundamental energy values defining their energy scale. This uncertainty is clearly comon to all $\gamma$-ray energles peasured on this scale and wust be 1dentifled in order that uncertainties may be properly combined. It is perhaps the lack of IIgor in obtaining welghted averages and in using a basic scale intermediately between the two energy sets which resulted in the work in the above references being refected by Kern.
\end{abstract}

Ge(L1) Y-Ray Energy Measurement Technique -- Uncertainty Components: In a precision Ge(Li) Y-ray-enerky ceasurement, data from an "unknown" source (suurce to be measured) and from a set of standard sources are accumulated simultaneously. Energy walues for $Y$ rays in the caknown source are then obtained by comparison with those of standaxd $y-r a y$ peaks in the spectrus.

Systen Nonlinearity: To ila1t the uncertainty due to system nonI1nearlty, the unknown fulienergy peak shoulu be relatively cloge to the standard peak to which it is being compared. A sufficlent number of adequately well known standards should cover the energy reglon of interest to permit thie nonlinearlty function to be deteralned. Since the electric fleld effect produces nonlinearity (Sanders, 1969), $Y$ rays from the unknown sources should enter the detector at the saue range of angles as those from the standards and preferably in a perpendicular direction with respect to the source.

Good technique must be used in developing the nonlinearity curve and handling the associated uncertainties. In order to take into account the coublned system nonlineartity, we fit by least-squares methods the energies of the standard $\gamma$ rays in each spertrum with a power series polynomiel of the form: $E_{1}=\sum_{n=0}^{N} A_{n} \cdot C_{1}^{n}$ where $E_{1}$ is the energy corresponding to the

channel $C_{1}$. For each of the standard sources, $\gamma$-ray energies and centrolds along with corresponding estimated standard deviations were input to a computer code. The appropriate standard deviation of the energies includes only messurement uncertalnties, not the reference component to the total uncertalnty. (Reference uncertalnties bear a common relationship to all of the standards and, hence, should not affect the weighting.) The code generates an error matrix which gives the total measurewent uncertaintles for any peak energy under consideration. This includes contributions due to the measurement uncertainty of the standard $\gamma$-ray energies, the peak fitting uncertalnties, and an uncertainty associated with interpolating between standard $Y$ rays. (The alze of the uncertainty envelope at a given energy depends or 1ts proximity to the standards.) For most spectra, a polynomial of order 4 or 5 proved to be adequate to fit the standard $\gamma$-ray energles as a function of centrold channel with an average deviation of less than that of the average statistical deviation of the measurement of the standard $y$-ray energies themselves. No apparent integral nonlinearity remained and the deviations frow the fit suggest that differential nonlinesrities are small.

Mddition of Uncertalnties in the Cascade-Crossover Methad: A problem in using the cascadecrossover method which 18 not fully appreciated is the complexity in the uncertainty analysis. Because of the interdependence of uncertaintles, a rigorous $\gamma$-ray energy uncertainty analysis, particularly when several cascades are involved, is very difficult. Consider a decay scheue for which we wish to determine the energy and uncertainty of the crossover $Y$ ray $\left(E_{Y 3} \pm \sigma_{Y 3}\right.$ ) by measuring the energles of two cascade $\gamma$ rays $\left(\gamma 1\right.$ and $\gamma 2$ ) with totel uncertalnties o ${ }_{\gamma}$ and oY 2 , respectively. Clearly 


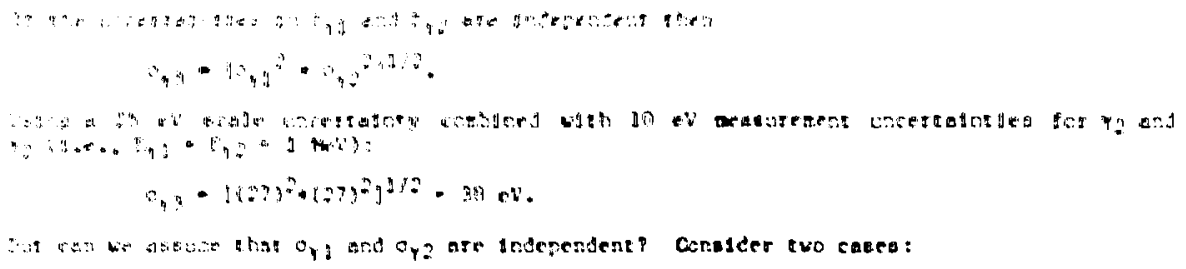

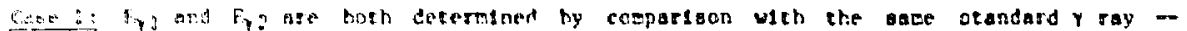

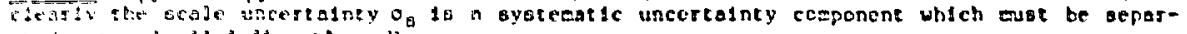
a: it cul and added ofrectly. hence

$$
\begin{aligned}
& o_{53}=0_{51}+0_{52}=2 o_{51} \\
& o_{m}=10_{m}{ }^{2}+\left.\sigma_{m^{2}}\right|^{1 / 2} \\
& \left.\sigma_{Y 3}=10_{M g^{2}}+\sigma_{s^{2}}\right]^{1 / 2} \text {. }
\end{aligned}
$$

where $c_{m 1} 18$ the masurecent uncertainty of the $1^{\text {th }} Y$ ray. For example:

$$
\sigma_{\gamma}=\left[(10)^{2}+(10)^{2}+(50)^{2}\right]^{1 / 2}-52 \mathrm{ev}
$$

an increase of $27 \%$ over the result obtained by disregarding systeatic components. If, however, $Y_{1}$ and $Y_{2}$ were compssed to different atandard 117es, the effect would be less serious.

Case 2: Consider the same cascade w1th $Y_{1}$ and $Y_{2}$ each close in energy to a different standard $\gamma$ ray. Can we now treat the uncertainties in the two standard $\gamma$-ray energles as being independent, giv:ug

$$
s_{S 3}=\left[\sigma_{S 1} 2+\sigma_{S 2} 2\right]^{1 / 2} ?
$$

We can only if ${ }^{\circ} \mathrm{S} 1$ and ${ }^{a} \mathrm{~S} 2$ have no common elements. However, this is not usually the case. If the two callbrated $Y$ rays have a common "ancester" (a standard $Y$ ray) from which their energies were obtained, then the uncertainty in the ancestor 18 common to both and 18 therefore a systematic uncertainty. Once this common element $1 \xi$ fgentified, then the uncertalnty in each stanjard $r$-ray energy is obtalned from $\sigma_{s}-\left[\sigma^{2}+n^{2}\right] 1 / 2$, where

0 I the systematic component of the uncertainty in the primary or Becondary 6 tandard, and

$\sigma \equiv$ the Independent component of the uncertainty in the standard.

The total uncertainty due to the standards becomes

$$
\sigma_{53}=\left[\sigma_{1} 1^{2}+\sigma_{2} 2^{2}+\left(\sigma_{2}+\sigma_{2}\right)^{2}\right]^{1 / 2} \text {. }
$$

Based on Helmer and coworkers, it is reasonable to assume that of the 25 eV uncertainty in the standard $\gamma$-ray energles, the syetematic component 18 at least $21 \mathrm{eV}$. Using this value along with other uncertainties used in Case 1 gives

$$
\left.\sigma_{S 3}-1(14)^{2}+(14)^{2}+(42)^{2}\right]^{1 / 2}=46 \mathrm{ev}
$$

and for the total uncertainty in the crossover $Y$ ray

$$
\sigma_{Y 3}=\left[(10)^{2}+(10)^{2}+(46)^{2}\right]^{1 / 2}=48 \mathrm{ev},
$$

which 18 still subgtantially higher than the $38 \mathrm{eV}$ obtalned when syntematic uncertafnty components were disregarded. Of course, the effect of incorrectly handling systematic uncertainties decreases rapidly with increasing measurement uncertainties. However, the effect also increases with $\gamma$-ray energy sface the uncertainty in the standard $\gamma$-ray energies $1_{6}$ dominated by the systematic component ance abou. $1 \mathrm{MeV}$.

The least-squates fitting proceriure frequently used to obtaln adjusted energles must be critica'ly examined. Because of the interdepentance of the uncertainties in the r-ray energies in-olved, it is not clear that the proper weights are ubed for the least-squares procedure. The uncertainty in the average level energg may be too amall because the assumptions concernlng the input uncertaintles are not valid. What is needed and certainly does not now exist. is a procedure for obtainting level energ'es in which the uncertainties are handled rigorously. 


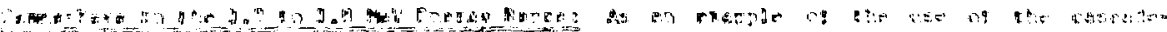

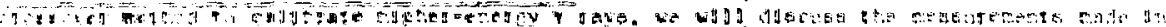

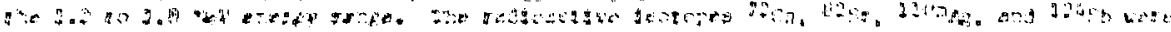

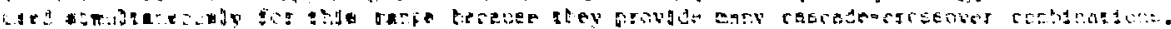

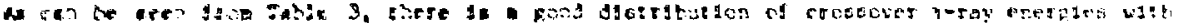

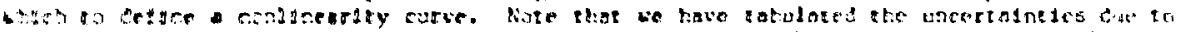

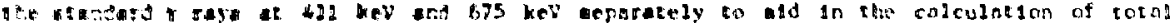

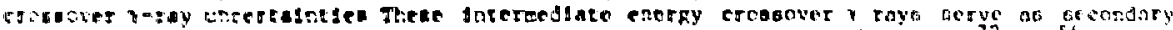

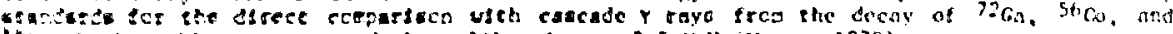

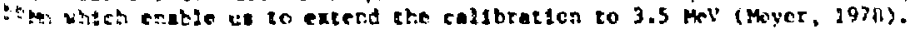

\section{TALE OF HLTIGAMA-RAY SOURC: VALUES AND INTERCOMPRISON}

in the apperdix we present our current y-ray energles and eatogion probabllity values for - rizser cf standerds. Sore of these have been cospared to other values in the literature (see e,R. Yostreva, 1982A, and Yosizaws, 1982B). As discussed earller our values for I5?Eu cCzpare well with the ICRM Intercalibration efforza (see Table 6 ). It should be noted that the r-ray exergy values aze deteralned Independently of the work of Helner and coworkers. Hence, they provide an Independent check on those values published after our orlginal work [e.R. see Greenwood, 1979] (see Table S).

\section{COUNTIEG GEONETRY}

A number of multigama-ray sources must be used only at large ( $>10$ cm) counting distances.

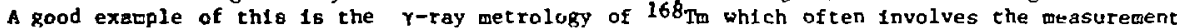
of ioractivity sources. The measurement of these lowactivity sources, in turn, requires that anall source-to-Ge(LI) detector distances be used. In such cases the reliance an Y-ray enission probabilities per decay may lead to incorrect results For 168Tu decay, a bajortcy of the transitions occur in such a way that severe suming can occur. This is 11lustrated in Table 6 where we compare the measurement of $168 \mathrm{Tm}$ at several different fourceto-detector distances. As can be seen in the labt colum in Table 6 , only three $Y$ rays exhiblt constant emission probabilities when the values for the $1.3-c 0$ counting distance is compared to the 88-col counting distance. Those are the 99-, 741-, and 821-kev $Y$ rays. The Ellght variation of the emisalon probabilitles for the 741 - and $821-k e v$ rays may be real o1nce the $741-\mathrm{keV} \gamma$ ray can sum with the $79-\mathrm{keV} \gamma$ ray tc produce an $821-k e V$ event. Thus, the slight diminishing of the $741-k e v$-ray emission probability et.uws up in the $821-k e V$ $\gamma$ ray. In general, we find that because of these effects and other counting effects, it 18 appropriate to calibrate the entire system of sample configiration, source-to-detector distance, and Ge(LI) detector efficlency for each measurement if precise results are required.

\section{REFERENCES}

Davidson, H. F., Warner, D. D., Casten, R. F., Schreckenbach, K., Börner, H. G., S1mic, J,, Stojanovic, M., Bogdanovich, M., S. Kolck1, S., Gelletly, W., Orr, G. B., and Stelts, F. L. (1981). J. Phys, G. 7, 455 (1981); and Errata, J. Phys, G. 7, 843 (1981). Debertin, K. (1979). Nucl. Instrum. and Meth. 15B, 479 (2979).

Greenwood, R. C., Helmer, R. G., and Gehrke, R.J. (1970). Nucl. Instrum. and Meth. 77,141 (1970).

Greenwood, R. C., Relmer, R. G., and Gehrke, R. J. (1939). Nucl, Instrum. and Meth. 159, 465 (1979).

Gunnink, R, and Niday, J. B. (1971, 1972), Lawsence LIvermore Nat1onal Laboratory Report VCRL-51061, Vol6. I-IV (1971, 1972).

Gunnink, R, and Niday, J. B. (1975). Lawrence Livermore National Laboratory Report UCRL-76699 (1975).

Gunn1nk, R. (1976). ERDA Symposium on Gammo-Ray Spectroscopy, Un1v. of Michigan (1976).

Gunnink, R. and Ruhter, H. D. (1980). Lawrence Livermore National Laboracory Report UICRL-52917 (1980).

Gunnirk, R., Ruhter, W. D., and N1day, J. B. (1983). Lawrence Livermore National Laboratory, Nuclear Chemisty D1v. Annual Report, FY 82, UCAR-10062-82/1 (1983).

Helmer, R. E., Greenwood, R. C., and Gehrke, R. J. (1971). Nucl. Instrum. and Heth. 96 , 173 (1971).

Hoff, P. (1980). Phys. Scr. 21, 129 (1980).

Kern, J. and Schwitz, W. (197B). Nucl. Instrum. and Meth. 151, 549 (1978).

Kegeler, E. G., Deslattes, R. D., HenIns, A., and Saunders, W. C. (1978). Phys, Rev, Lett. $40,171(1978)$.

Krusche, B., Lleb, R. P., Danfel, H., von Egldy, T., Barreau, G., Börner, H. G., Brissot, R. (1982). Nuc1. Phye. A386, 245 (1982).

LIn, J., Fenry, E., and Meyer, R. A. (1980). Lawrence Liverwore National Laboratory Report UCRL-84536 (1980).

Loper, G. D. and Thomas, G. E. (1972). Nucl. Instruw. and Meth. 105, 453 (1972).

MeCalium, G. J. and Coote, G, E. (1975). Nucl. Instrum, and Meth.124, 309 (1975).

Meyer, R. A., Tirbell, R. G., and Armantrout, G. A. (197a). Latrence Lfverzore National Laboratory Report DCRL-78222 (1976). 


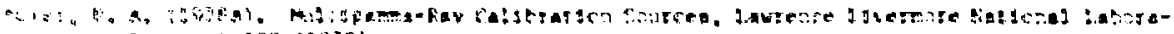

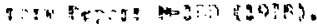

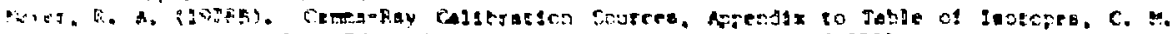

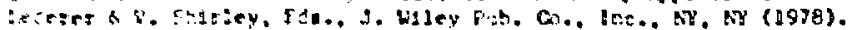

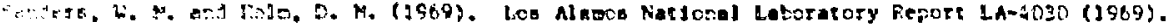

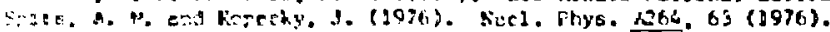

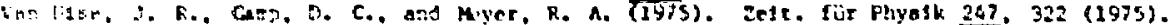

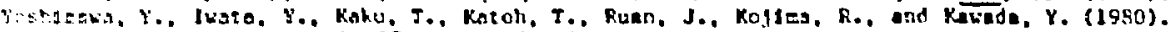

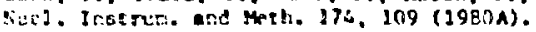

Yosplzews, Y.. Iwata, Y., and I1nues, Y. (19E0). Nuel. Inserug, and Heth. 174, 133 (19808).

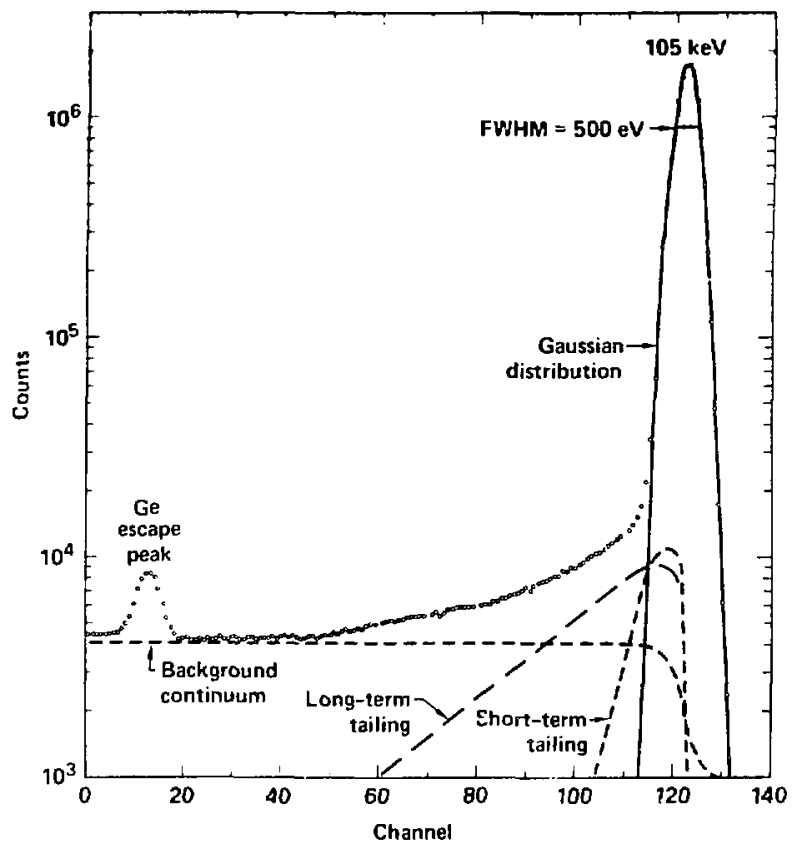

F1f. 1. Illustration of peak shape features used in GAMANAL analyais (taken from Gunnink, 1971/72, Gunnink, 1975, Gunnink, 1980). 

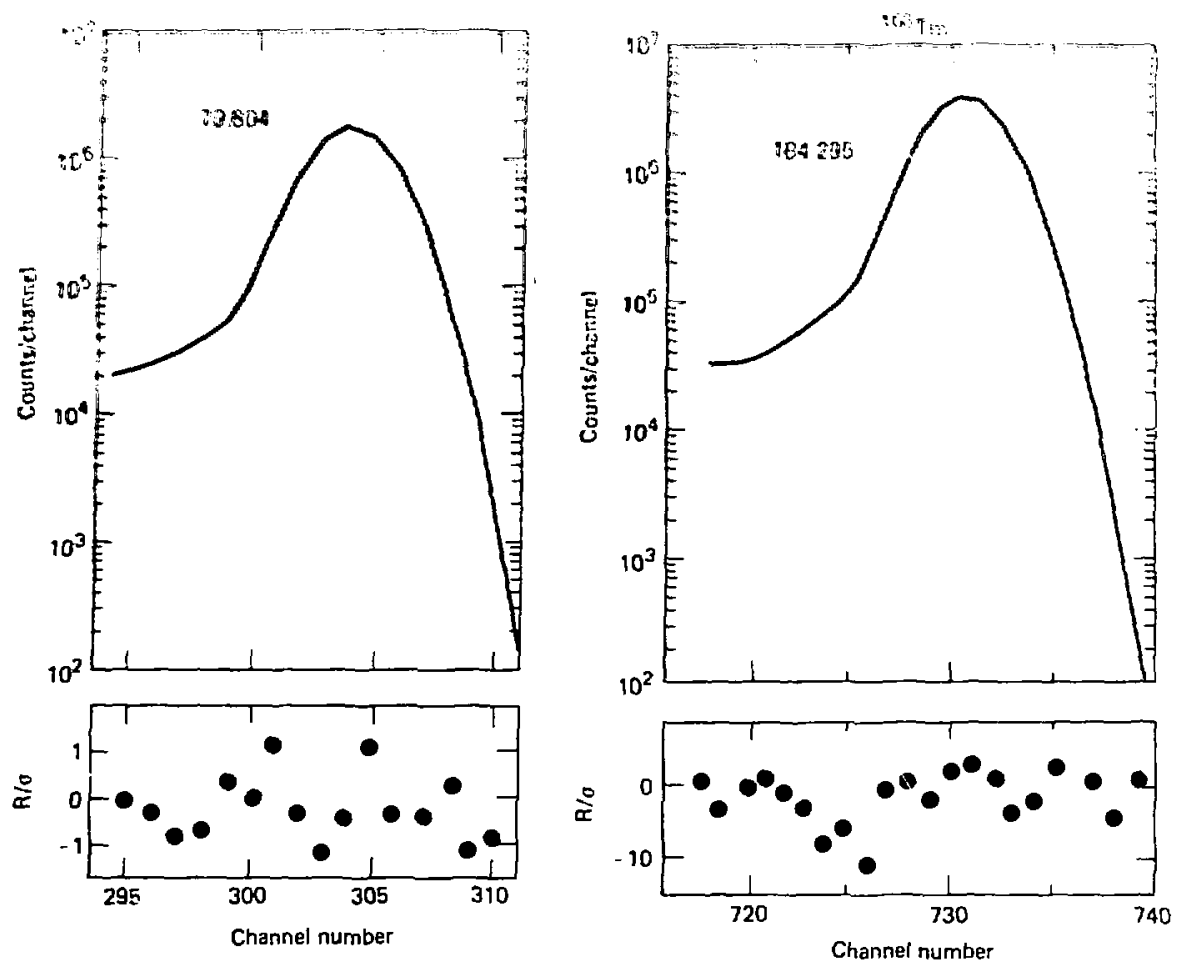

F1g. 2. GAMANAL peak thape f1e to 79.804keV phoropeak of 168 Tm (showing excess of $10^{6}$ counts in peak chennel).

Fig. 3. GaMANaL peak shape f1t to $184.295-$ key photopeak of 168 Tm (nore number events per channel exceeds $10^{6}$, see (ext).

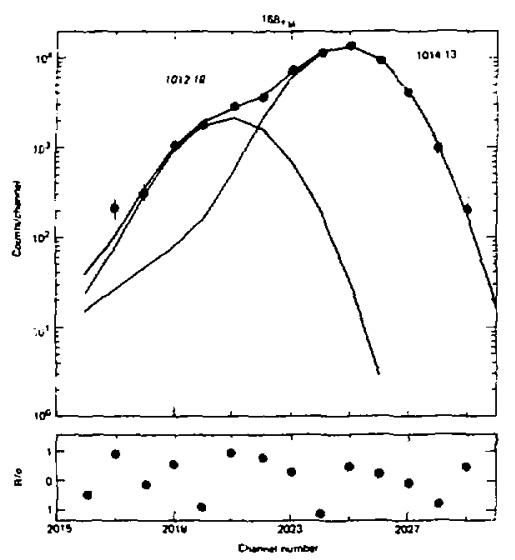

FIR. 4. GAMANAL peak shape f1t to doublet with lower-energy lower-emisalonrate component ( $168_{\text {Tu decay). }}$

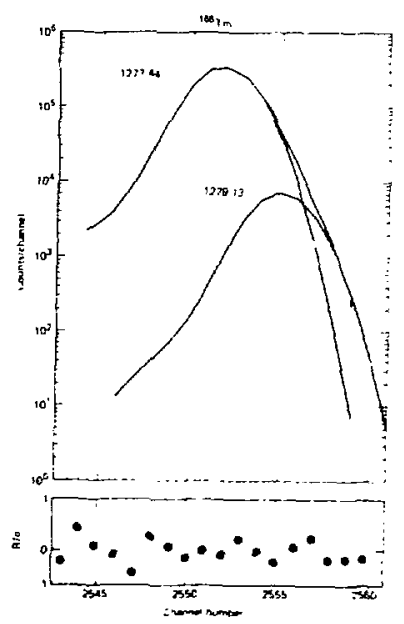

Fig. 5. CAMANAL peak shape fit to doublet wth higher-energy Iower-emissionrate component ( 168 Tn decay). 


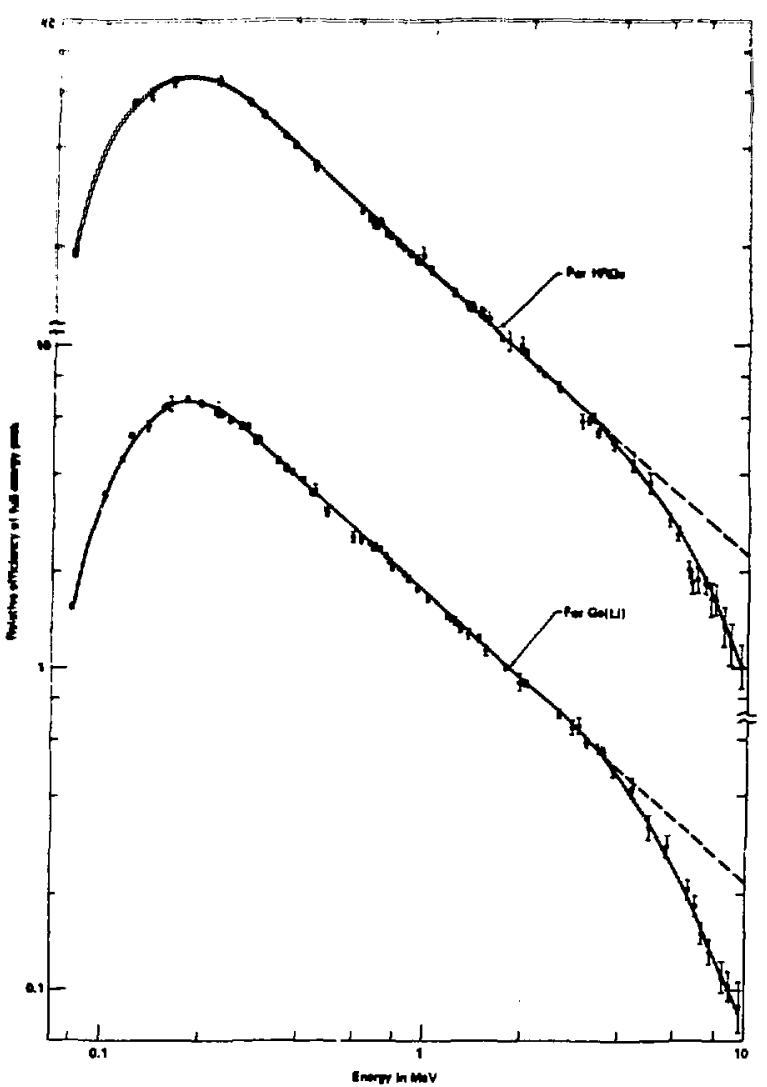

F1g. 6. Relative effictency curves. The upper curve is for the highpurity $G e$ deteclor and the bottor one is for the Ge(I1)

detector. Both detectors with $x$-ray absorbers were placed at $32 \mathrm{~cm}$ to the target.

Table 1. Coefflclents of Polynomials for Relative Efficlency Curves $\ln E_{1}=\sum_{J=1, G} a_{I}\left(1 n E_{1}\right)^{j-1}$

High-Purity ge with x-ray absorber

$80 \quad 1.000 \quad 700 \quad 10,000$

$a_{1} 5.583484 \times 10^{-1}$

$a_{2}-8.143926 \times 10^{-1}$

$a_{3}-4.716715 \times 10^{-2}$

$a_{4}-2.65: 550 \times 10^{-1}$

$a_{5}-1.457360 \times 10^{-1}$

${ }_{6}$

$$
\frac{(\mathrm{keV})}{5.554820 \times 10^{-1}}
$$

$$
-8.513116 \times 10^{-1}
$$$$
-4.417474 \times 10^{-2}
$$$$
-3.969594 \times 10^{-1}
$$$$
2.453228 \times 10^{-1}
$$$$
-1.497802 \times 10^{-2}
$$

Ge(li) with x-ray absorber

$$
\begin{array}{rrr}
80 & \begin{array}{c}
1.000 \\
(\mathrm{kev})
\end{array} & \frac{700}{(\mathrm{keV})} \\
\hline 5.454347 \times 10^{-1} & 5.425167 \times 10^{-1} \\
-8.200305 \times 10^{-1} & -9.039662 \times 10^{-1} \\
-8.378286 \times 10^{-2} & 1.493954 \times 10^{-2} \\
-3.384564 \times 10^{-1} & 2.451231 \times 10^{-1} \\
-1.741303 \times 10^{-1} & -2.886225 \times 10^{-1} \\
0 & 6.229419 \times 10^{-2}
\end{array}
$$




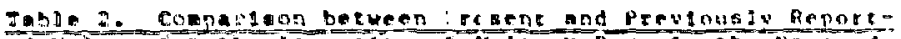

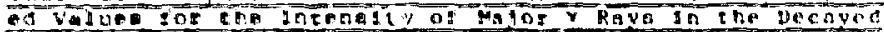

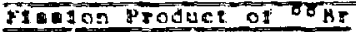

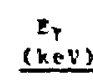

460
610
764
775
802
669
1053
1074
1147
1352
1694
1855
2053
2215
2624
2875
2934
2946
3279
3933
4018
4721
$6999.2(2)$

\begin{tabular}{|c|c|}
\hline previoust & Pregent wor \\
\hline $\begin{array}{c}0.97(2) \\
-.0 \\
1.0(3) \\
=100.0(26) \\
20.8(6) \\
5.39(9) \\
2.07(1) \\
1.65(4) \\
-. . \\
1.05(10) \\
5.2(4) \\
1.66(8) \\
0.92(4) \\
0.83(5) \\
2.52(7) \\
2.52(9) \\
2.38(9) \\
3.12(10) \\
2.99(11) \\
5.38(15) \\
2.81(12) \\
1.45(5) \\
0.28(3)\end{array}$ & $\begin{array}{l}0.83(4) \\
1.68(4) \\
2(6) \\
\equiv 200.0(3) \\
20.5(5) \\
5.28(6) \\
2.3(3) \\
2.8(1) \\
0.95(7) \\
1.2(2) \\
4.0(3) \\
2.2(1) \\
0.8(1) \\
0.9(1) \\
2.6(2) \\
3.2(2) \\
2.9(2) \\
4.3(2) \\
3.8(3) \\
7.5(3) \\
3.3(3) \\
1.5(4) \\
0.44(3)\end{array}$ \\
\hline
\end{tabular}

arelative intensity normalized to 100 for the 775-kev y ray. bTaken from Hoff (1980).

Table 3. Gamma-ray Cascade and Crossover Transitions used $1 \pi$ the 1.2 to 1.8 MeV (Uncerta!nty Components in eV)

\begin{tabular}{|c|c|c|c|c|c|c|}
\hline Isotope & $\begin{array}{c}\text { Croggover } \\
(\mathrm{kev}) \\
\end{array}$ & Meagure & $675^{\circ}$ & $411^{\mathrm{a}}$ & Tota 1 & $\begin{array}{l}\text { Cascac: } \\
\text { Y rays } \\
\end{array}$ \\
\hline$B r-82$ & 1317.473 & 5 & $B$ & 16 & 19 & $619+698$ \\
\hline$A g-110 D$ & 1384.305 & ô & B & 17 & 20 & $\begin{array}{l}827+1043-544 \\
, 77+706\end{array}$ \\
\hline & & & & & & $\begin{array}{l}620+763 \\
446+937\end{array}$ \\
\hline $6 a-7 ?$ & 1464.084 & 11 & 8 & 18 & 23 & $629+834$ \\
\hline$A p-110 m$ & 1505.039 & 8 & 16 & 18 & 25 & $\begin{array}{l}620+884 \\
686+818\end{array}$ \\
\hline$A g-110 m$ & $1562.30 \%$ & 11 & 16 & 19 & 27 & $\begin{array}{l}744+818 \\
677+884\end{array}$ \\
\hline $\begin{array}{l}G a-72 \\
S b-124\end{array}$ & $\begin{array}{l}1596.744 \\
1690.99 .\end{array}$ & $\begin{array}{l}11 \\
10\end{array}$ & $\begin{array}{l}16 \\
16\end{array}$ & $\begin{array}{l}19 \\
20\end{array}$ & $\begin{array}{l}27 \\
27\end{array}$ & $\begin{array}{l}786+810 \\
645+1045\end{array}$ \\
\hline
\end{tabular}

avreertainty due to standard $Y$ rays at 675 and 411 kev. 


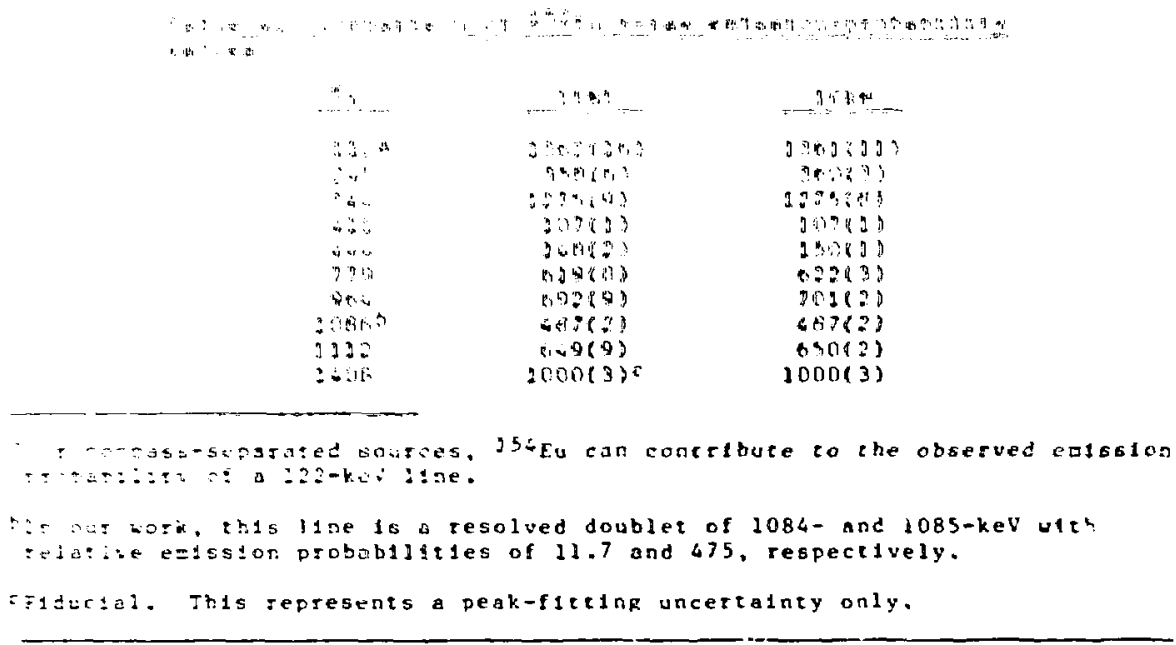

zable 5. Comparsson tor r R-ray Energies of 56Co in keV

$$
\frac{\text { LLNE }}{E_{\gamma}\left(\Delta E_{Y}\right)}
$$

$846.772(8)$

$1037.840(6)$

$1175.102(6)$

$1238.282(7)$

$1360.215(12)$

$1271.351(36)$

$2015.181(16)$

$2034.755(15)$

$2598.458(13)$

$3009.591(22)$

$3201.962(36)$

$3253.416(15)$

$3272.990(15)$

$3551.152(17)$

$3547.925(61)$
Helaer (1979)

$E_{Y}\left(\Delta E_{Y}\right)$

$846.764(6)$

$1037.844(4)$

$1175.099(8)$

$1238.287(6)$

$1360.206(6)$

$1771.350(15)$

$2015.179(11)$

$2034.159(11)$

$2598.460(10)$

$3009.596(17)$

$3201.954(14)$

$3253.417(14)$

$3272.99 B(14)$

$3451.154(13)$

Tahle 5A. Compartgon of $Y$ R-ray Energleg for $110_{\text {Ag }}$ in ke $\because$

$$
\begin{aligned}
& \frac{L L N L}{E_{Y}\left(\Delta E_{Y}\right.} \\
& 446.808(8) \\
& 620.362(1) \\
& 657.766(5) \\
& 677.623(7) \\
& 687.005(11) \\
& 706.68 B(B) \\
& 744.279(8) \\
& 763.947(8) \\
& 81 B .037(8) \\
& 884.689(8) \\
& 937.502(13) \\
& 1384.305(8) \\
& 1475.305(12) \\
& 1505.039(8) \\
& 1562.305(9)
\end{aligned}
$$

$\frac{\text { Kern and }}{E_{Y}\left(\Delta E_{Y}\right)} \frac{\text { Schw1tz }}{E_{\gamma}}$

$446.815(4)$

$620.359(3)$

$657.761(2)$

$677.625(4)$

$687.012(4)$

$706.678(5)$

$744.27 \mathrm{~B}(5)$

$763.944(4)$

B] $8.029(5)$

$884.682(5)$

$937.488(5)$

$1384.299(4)$

$1475.785(5)$

$1505.036(5)$

j562.301(6) 


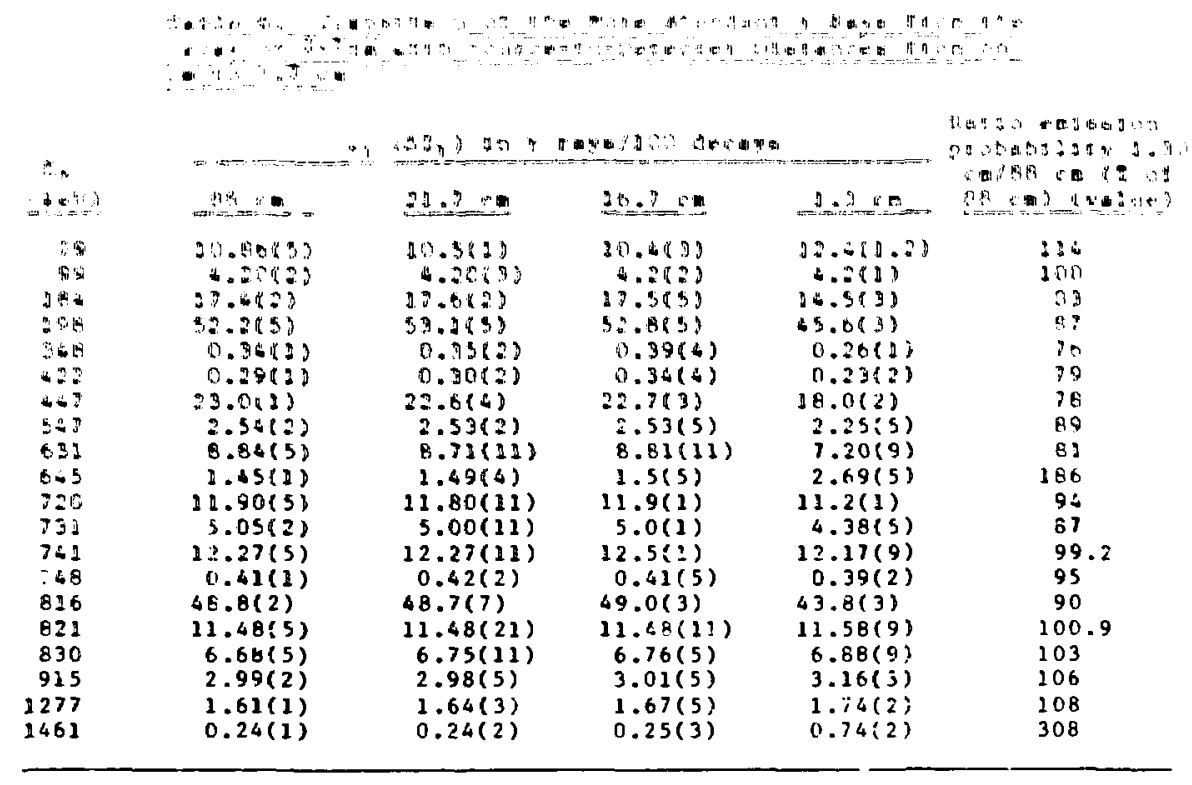

\section{APPENDI $R$}

${ }^{44} \mathrm{Sem}+8$ ( $58.6 \mathrm{~h}$ and $3.93 \mathrm{~h}$; frow (7Y 44T1)

$\frac{E_{Y}\left(\Delta E_{Y}\right)}{271.248(10)}$
$1001.850(31)$
$1126.092(40)$
$1157.031(15)$
$1499.489(25)$
$2144.3(1)$
$2150.840(22)$
$2656.478(30)$
$3301.3(1)$

$\frac{I_{\gamma}\left(\Delta I_{\gamma}\right)}{778(14)}$
$12.3(1)$
$12.3(1)$
$1000(3)$
$9.0(2)$
$0.02(2) b$
$0.011(3)$
$1.11(4)$
$0.0064(8)$

athe $\gamma$-ray energy 18 from $44 \mathrm{~K}$ decay.

bInterference fron the natural background precluded obtaining a precise value.

\begin{tabular}{cc}
\hline $4 B_{S C}(43.8 \mathrm{~h})$ & \\
$E_{Y}\left(\Delta E_{Y}\right)$ & $I_{Y}\left(\Delta I_{Y}\right)$ \\
\hline $175.361(5)$ & $74.7(9)$ \\
$983.526(12)$ & $1000(3)$ \\
$1037.522(12)$ & $975(5)$ \\
$1212.880(12)$ & $23.8(4)$ \\
$1312.12 n(12)$ & $1000(5)$ \\
\hline
\end{tabular}

$\begin{array}{lcl}48 V(16.214) & & 28 \\ E_{Y}\left(4 E_{Y}\right) & & 44 \\ 803.25(8) & -I_{\gamma}\left(\Delta I_{\gamma}\right) & 48 \\ 928.327(9) & 1.5(2) & 48 \\ 944.125(7) & 7.7(5) \\ 983.526(5) & 77.6(9) & \\ 1.063 .9(1) & 1000(2) & 0.05(1) \\ 1312.090(12) & 975(8) & 1.2(2) \\ 1437.35(7) & 24.1(4) \\ 2240.398(10) & 0.10(5) \\ 2375.1(5) & 0.10(5) \\ 2421.8(5) & & \\ & \end{array}$

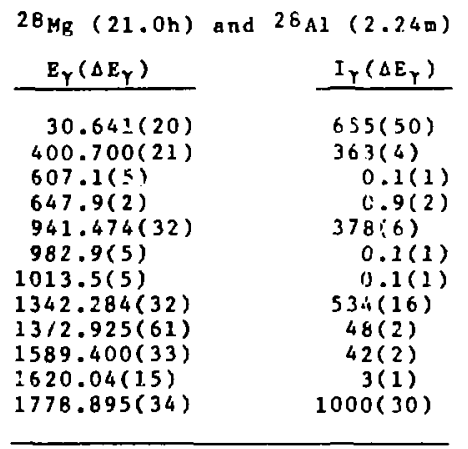




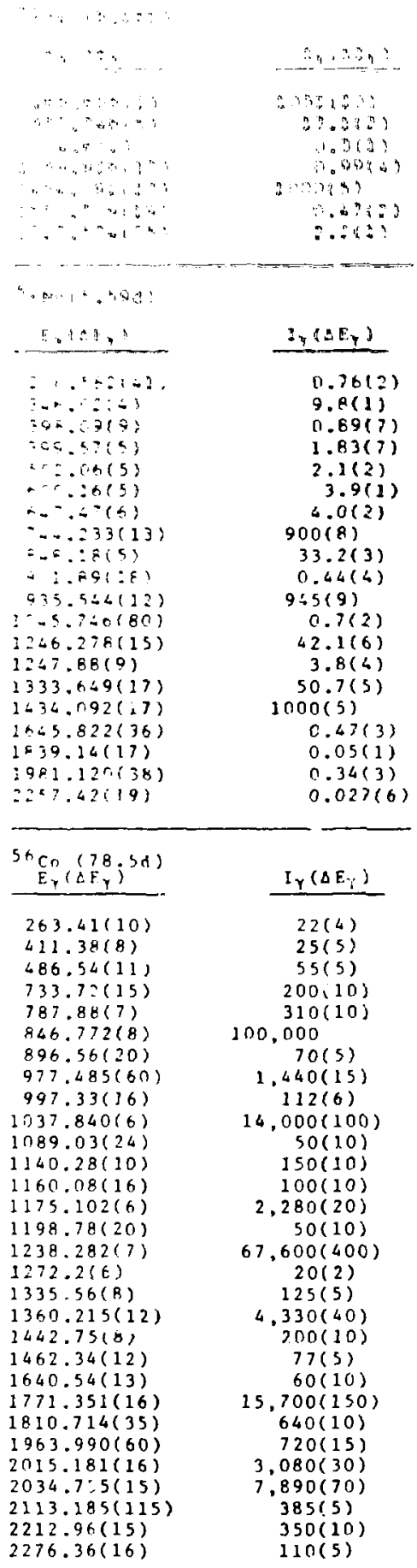

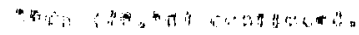

Fn?

$9379.75(10)$

709.90250

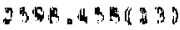

309.914 की

$350.940014)$

$3253.40(15)$

2.7?.900453)

$330.00(30)$

$3651.152117)$

$3547.925(41)$

$3600.69(40)$

ำ

$(290)$

+115)

27.401403

3.

9. 3400901

7.935 (6)

0.8001502

211:3

$950(18)$

$198(5)$

18(1)

$67 \mathrm{C} \cdot(78.3 \mathrm{~h})$

\begin{tabular}{r}
$E_{Y}\left(A E_{Y}\right)$ \\
\hline $91.237(35)$ \\
$93.291(30)$ \\
$184.569(30)$ \\
$208.930(30)$ \\
$300.230(25)$ \\
$393.539(25)$ \\
$494.132(30)$ \\
$703.078(50)$ \\
$794.378(50)$ \\
$887.664(40)$
\end{tabular}

$I_{V}\left(\Delta E_{Y}\right)$

$30(2)$

$356(14)$

$217(9)$

$24(1)$

$166(4)$

45(1)

$0.7(1)$

$0.10(1)$

$0.53(3)$

$1.49(5)$

\begin{tabular}{cc}
\hline 75 Se $(1208)$ & \\
$E_{Y}\left(\Delta E_{Y}\right)$ & $I_{Y}\left(\Delta E_{Y}\right)$ \\
\hline $24.391(55)$ & $0.46(4)$ \\
$66.061(6)$ & $18.7(1)$ \\
$80.937(30)$ & $0.19(4)$ \\
$96.734(3)$ & $57.2(21)$ \\
$121.121(4)$ & $298 .(2)$ \\
$135.999(2)$ & $1000(3)$ \\
$198.596(8)$ & $25.4(2)$ \\
$264.658(3)$ & $1000(5)$ \\
$279.535(5)$ & $422(4)$ \\
$303.923(5)$ & $22.3(2)$ \\
$400.657(2)$ & $195(3)$ \\
$419.302(45)$ & $0.18(3)$ \\
$572.724(20)$ & $0.60(3)$ \\
$617.896(35)$ & $0.077(4)$ \\
$821.916(35)$ & $0.0022(2)$ \\
&
\end{tabular}

$82 \mathrm{Br}(35.30 \mathrm{~h})$

$\begin{array}{cc}E_{Y}\left(\Delta E_{Y}\right) & I_{Y}\left(\Delta E_{Y}\right) \\ 92.190(16) & 9.0(3) \\ 100.890(70) & 0.84(8) \\ 129.29(10) & 0.36(7) \\ 237.40(5) & 1.8(2) \\ 179.8(2) & 0.12(9) \\ 221.459(25) & 27.2(8) \\ 273.480(9) & 20.0(5) \\ 280.7(2) & 0.15(4) \\ 332.897(31) & 1.08(5) \\ 401.16(6) & 1.09(9) \\ 470.29(9) & 0.6(2) \\ 554.353(7) & B 48(16) \\ 559.5(3) & 0.16(9) \\ 606.369(20) & 14.5(4) \\ & \end{array}$




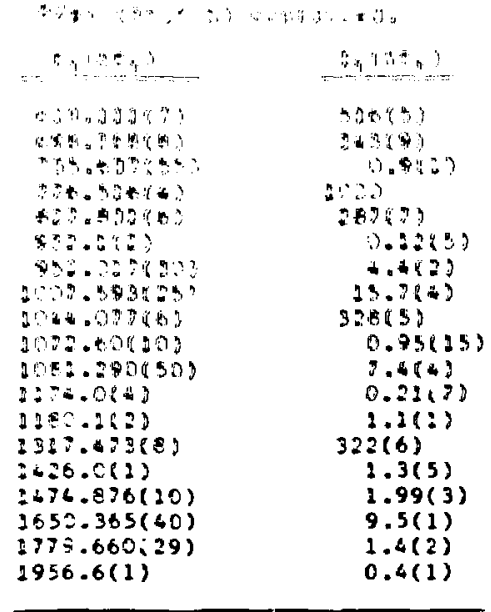

$B 3_{R b}(83 d)$

\begin{tabular}{cc}
$E_{Y}\left(\Delta E_{Y}\right)$ & $I_{Y}\left(\Delta E_{Y}\right)$ \\
\hline $9.390(90)$ & $131(30)$ \\
$32.181(50)$ & $0.8(1)$ \\
$119.323(90)$ & $0.32(5)$ \\
$128.55(12)$ & $0.030(5)$ \\
$520.423(25)$ & $1000(5)$ \\
$529.653(11)$ & $656(30)$ \\
$552.664(21)$ & $357(15)$ \\
$562.174(70)$ & $0.19(2)$ \\
$648.976(50)$ & $1.9(1)$ \\
$681.187(65)$ & $0.7(1)$ \\
$790.160(35)$ & $14.7(4)$ \\
$799.380(51)$ & $5.3(2)$ \\
& \\
\hline
\end{tabular}

$957 \mathrm{r}(64.0 \mathrm{~d})$

$\begin{array}{lc}E_{Y}\left(\Delta E_{Y}\right) & 1_{Y}\left(\Delta E_{Y}\right) \\ 235.696(20) & 0.24(1) \\ 724.202(12) & 43.7(8) \\ 756.734(15) & 55.4(1.1)\end{array}$

athe values ouoted are the emisolon probajility per 100 decays.

$105_{A g}(41.0 d)$

\begin{tabular}{cc}
$E_{Y}\left(\Delta E_{Y}\right)$ & $I_{Y}\left(\Delta I_{Y}\right)$ \\
\hline $38.771(70)$ & $0.13(2)$ \\
$64.072(70)$ & $268(5)$ \\
$90.012(70)$ & $0.8(1)$ \\
$122.51(5)$ & $0.84(6)$ \\
$155.38(5)$ & $9.8(2)$ \\
$159.00(8)$ & $0.75(9)$ \\
$182.92(3)$ & $B .6(2)$ \\
$202.21(9)$ & $0.9(2)$ \\
$216.1(2)$ & $0.33(7)$ \\
$270.5(2)$ & $0.3(1)$ \\
$280.54(2)$ & $744(4)$ \\
$284.8(1)$ & $2.3(5)$ \\
$289.38(8)$ & $2.9(2)$
\end{tabular}

$: 1$

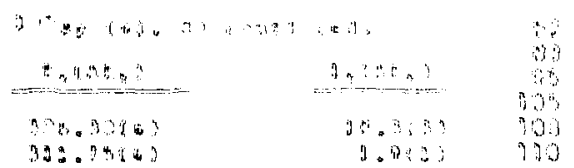

3.9 .2413

30.4 .403

320.0203

$393.912 \pm 3$

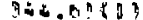

353.0431

$300.53 \times 3)$

$300.29(3)$

$392.74(2)$

$402.76(4)$

$408.09(8)$

$414.86(5)$

$421.04(6)$

$437.31(4)$

$483.45(1)$

$446.8(1)$

$527.35(8)$

$560.80(B)$

$576.7(2)$

$610.0(3)$

$617.92(4)$

$640.5(2)$

$644.65(3)$

$650.80(4)$

$673.26(5)$

$681.96(9)$

$709.8(3)$

$727.29(9)$

$743.47(8)$

$768.9(3)$

$807.59(5)$

$844.6(2)$

$921.2(2)$

$929.2(2)$

$962.47(9)$

108 B.08(4)

$1125.3(3)$

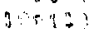

4. 533

4.0203

$\left.9 p^{2}+5,5\right)$

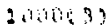

(9. 2)1

a. 3 C

17. का?

$4 . B(4)$

$4.0(1)$

$2.0(2)$

$7.2(2)$

$2.9(1)$

$0.9(2)$

$259(2)$

$2.4(2)$

$2.6(2)$

$13.5(1)$

$0.6(1)$

$0.2(1)$

$28.6(3)$

$0.7(2)$

$242(2)$

$60.0(6)$

$23.3(4)$

$1.8(4)$

$0.16(8)$

$3.5(1)$

$12.7(3)$

$0.24(8)$

$27.5(6)$

$0.6(1)$

$0.4(1)$

$0.33(8)$

2 . : (1)

86(1)

$0.27(5)$

108 Ag $^{\text {m }}(130 y)$

$\frac{E_{Y}\left(\Delta E_{Y}\right)}{433.939(4)}$
$614.281(6)$
$633.012(38)$
$722.938(8)$

$I_{Y}\left(\Delta I_{Y}\right)$

991(3)

$997(3)$

1.51(B)

$1000(3)$

$110 \mathrm{Ag}^{\mathrm{m}}(252 \mathrm{~d})$

\begin{tabular}{l}
$E_{Y}\left(\Delta E_{Y}\right)$ \\
\hline $116.485(46)$ \\
$120.226(26)$ \\
$133.333(7)$ \\
$219.348(8)$ \\
$221.079(10)$ \\
$229.423(23)$ \\
$264.254(58)$ \\
$266.913(12)$ \\
$341.2(2)$ \\
$356.43(10)$ \\
$360.228(75)$ \\
$365.450(11)$ \\
$387.075(9)$ \\
$396.897(23)$
\end{tabular}

$I_{Y}\left(\Delta I_{Y}\right)$

$0.085(3)$

$0.19(1)$

$0.77(3)$

$0.70(2)$

$0.72(1)$

$0.128(B)$

$0.059(5)$

$0.43(1)$

$0.022(4)$

$0.045(4)$

$0.035(7)$

$1.02(8)$

$0.55(1)$

$0.43(1)$ 


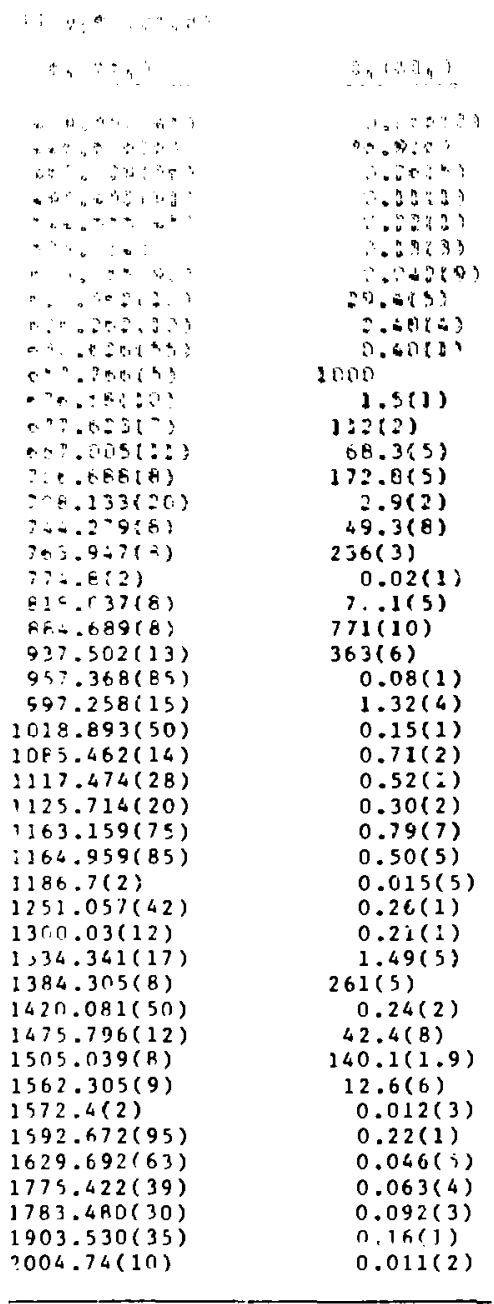

$90 \mathrm{NB}(14.6 \mathrm{~h})$

$\frac{F_{Y}\left(\Delta E_{Y}\right)}{132.716(18)}$
$141.178(15)$
$329.058(16)$
$337.50(15)$
$371.307(B)$
$420.280(50)$
$425.5(2)$
$518.597(58)$
$561.604(11)$
$757.949(44)$
$792.05(19)$
$827.744(36)$
$890.644(41)$
$1151.532(33)$
$1057.8(1)$
$1093.144(82)$

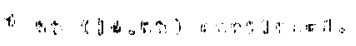

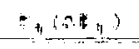

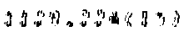

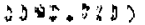

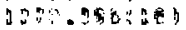

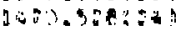

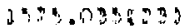

$1491.20: 230 ?$

$36.0 .09739)$

$1020.200(20)$

$2043.342(22)$

$1913.191(23)$

$190 . .535(20)$

$2000.18(29)$

$050.095(75)$

$2186.242(25)$

$2222.343(28)$

$2316.959(25)$

$2321.9(2)$

$2741.0(3)$

$2767.8(3)$

$$
\begin{aligned}
& \text { I } 19: 2 \\
& 299.99
\end{aligned}
$$

\begin{tabular}{|c|c|}
\hline$E_{Y}\left(\Delta E_{Y}\right)$ & $I_{\gamma}\left(\Delta I_{\gamma}\right)$ \\
\hline $\begin{array}{l}108.95(11) \\
219.081(18) \\
241.377(15) \\
314.337(71) \\
316.271(87) \\
350.053(19) \\
352.555(28) \\
371.807(15) \\
434.730(37) \\
460.040(12) \\
480.705(17) \\
568.871(12) \\
591.243(48) \\
719.562(17) \\
721.629(19) \\
778.224(15) \\
810.330(15) \\
812.581(15) \\
847.687(22) \\
849.929(13) \\
1019.611(28) \\
1052.57(11) \\
1091.349(12) \\
1126.965(21) \\
1149.847(96) \\
1200.231(13) \\
1368.79(12) \\
1497.807(15) \\
1441.129(24) \\
1588.377(28) \\
1625.903(47) \\
1627.803(22) \\
1807.70(10) \\
1869.207(58) \\
1978.191(71)\end{array}$ & $\begin{array}{c}0.46(15) \\
30.8(5) \\
40.0(7) \\
0.77(14) \\
0.63(9) \\
16.0(4) \\
8.6(4) \\
27.2(9) \\
3.9(3) \\
276(2) \\
60.5(5) \\
601(3) \\
9.7(9) \\
71.0(9) \\
10.6(6) \\
1000(2) \\
115(1) \\
30.6(8) \\
11.8(6) \\
212(2) \\
2.1(1) \\
0.63(12) \\
5.1(1.5) \\
4.4(2) \\
0.54(11) \\
207(1) \\
0.43(9) \\
34.0(7) \\
4.6(2) \\
2.6(1) \\
1.6(1) \\
3.9(1) \\
0.59(8) \\
11(1) \\
3.8(3)\end{array}$ \\
\hline
\end{tabular}

$1000(2)$

$9(2)$

$0.09(3)$

$0.06(2)$

96 \%о $(23.35 \mathrm{~h})$
9.9

a) 

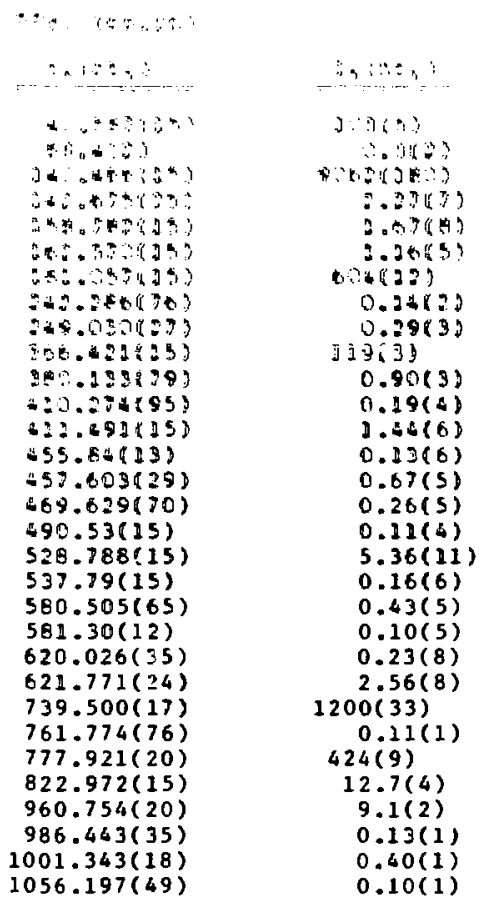

$103_{R+1}(39.35 d)$

\begin{tabular}{l}
$E_{Y}\left(\Delta E_{Y}\right)$ \\
\hline $39.731(50)$ \\
$42.631(41)$ \\
$53.291(10)$ \\
$113.253(70)$ \\
$114.973(22)$ \\
$241.886(52)$ \\
$292.7(2)$ \\
$294.987(27)$ \\
$317.8(2)$ \\
$357.399(140)$ \\
$443.811(20)$ \\
$497.813(19)$ \\
$514.60(15)$ \\
$554.054(17)$ \\
$567.88(13)$ \\
$610.345(22)$ \\
$612.035(31)$ \\
$651.8(4)$ \\
\end{tabular}

$113 \mathrm{Sp}$ (115d)

$\frac{E_{Y}\left(\Delta E_{Y}\right)}{255.066(50)}$
$391.698(15)$
$638.046(75)$
$646.8(1)$

\begin{tabular}{c}
$I_{Y}\left(\Delta E_{Y}\right)$ \\
\hline $0.79(5)$ \\
$0.012(2)$ \\
$4.2(2)$ \\
$0.040(8)$ \\
$0.089(8)$ \\
$0.17(2)$ \\
$0.03(3)$ \\
$2.80(9)$ \\
$0.06(1)$ \\
$0.10(3)$ \\
$3.6(11)$ \\
$1000(5)$ \\
$0.054(15)$ \\
$9.3(3)$ \\
$0.018(8)$ \\
$63(2)$ \\
$0.9(1)$ \\
$0.0019(8)$
\end{tabular}

$\frac{I_{Y}\left(\Delta I_{Y}\right)}{28.5(7)}$
$1000(3)$
$0.0149(5)$
$0.00006(3)$

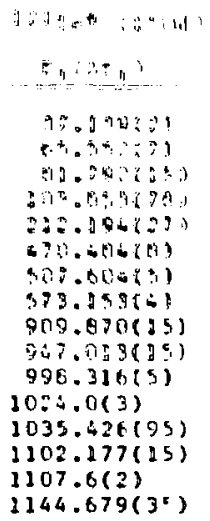

$124 \mathrm{sb}\left(60.2^{n} \mathrm{~d}\right.$

$$
E_{Y}\left(\Delta E_{Y}\right)
$$

$400.010(60)$

$443.961(50)$

$525.410(50)$

$602.728(5)$

$632.386(45)$

$645.858(6)$

$709.320(13)$

$713.793(6)$

$722.789(6)$

$735.738(26)$

$790.727(16)$

$968.208(7)$

$976.23(11)$

$1045.138(20)$

$1325.516(8)$

$1355.275(22)$

$1368.179(30)$

$1376.112(45)$

$1436.577(12)$

$1445.058(39)$

$1488.886(24)$

$1526.177(47)$

$1570770(47)$

$1690.992(16)$

$1919.82(20)$

$2039.299(30)$

$2090.962(35)$

$2099 . \mathrm{J},(10)$

$2108.080(80)$

$2182.610(90)$

$2283.30(10)$

$2293.710(40)$

$2323.1(3)$

$2454.4(4)$

$2682.0(4)$

$2693.680(60)$

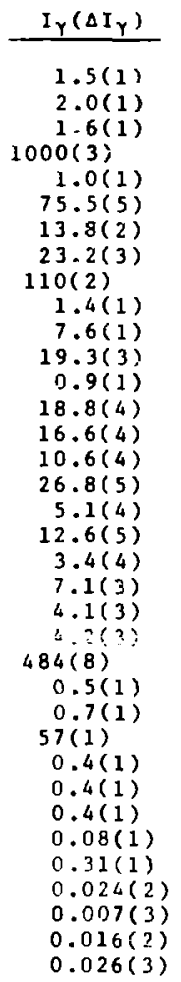

$125 \mathrm{sb}(2.73 y)$

\begin{tabular}{ll}
$E_{Y}\left(\Delta E_{Y}\right)$ & $I_{Y}\left(\Delta E_{Y}\right)$ \\
\hline $110.895(12)$ & $0.009(1)$ \\
$116.955(11)$ & $2.55(4)$ \\
$145.08(10)$ & $0.0062(4)$ \\
$172.619(15)$ & $1.82(3)$
\end{tabular}




\begin{tabular}{|c|c|}
\hline$\therefore: \therefore a$ & $3, \ldots 81$ \\
\hline 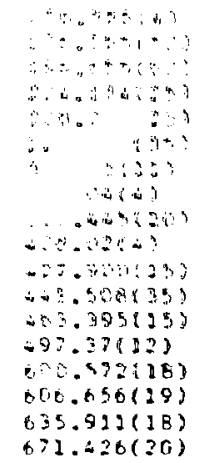 & 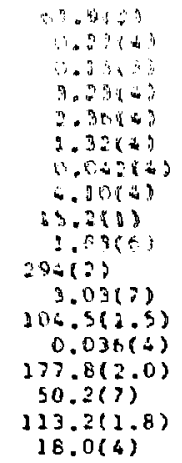 \\
\hline \multicolumn{2}{|l|}{$1201(13.00)$} \\
\hline$E_{Y}\left(\Delta E_{Y}\right)$ & $I_{Y}\left(\Delta E_{Y}\right)$ \\
\hline $\begin{array}{l}388.643(5) \\
491.255(6) \\
666.348(6) \\
695.0(1) \\
753.838(7) \\
879.896(8) \\
1206.8(3) \\
1420.23(3) \\
2045.14(5)\end{array}$ & $\begin{array}{c}1030(5) \\
86.1(3) \\
1000(3) \\
0.007(3) \\
125.8(6) \\
22.8(6) \\
0.014(4) \\
8.91(5) \\
0.16(1)\end{array}$ \\
\hline \multicolumn{2}{|l|}{$131 \mathrm{I}(8.041 \mathrm{~d})$} \\
\hline$E \cdot\left(\Delta E_{Y}\right)$ & $I_{Y}\left(\Delta E_{Y}\right)$ \\
\hline $\begin{array}{l}80.185(2\} \\
85.9(2) \\
177.214(2) \\
232.18(15) \\
272.498(17) \\
284.305(5) \\
295.8(2) \\
302.4(2) \\
318.088(12) \\
324.652(25) \\
325.789(4) \\
358.4(2) \\
364.489(5) \\
404.814(4) \\
449.6(2) \\
503.004(4) \\
636.989(4) \\
642.719(5) \\
722.911(5)\end{array}$ & $\begin{array}{c}26.0(3) \\
0.0009(5) \\
2.63(2) \\
0.014(18) \\
0.56(1) \\
60.1(6) \\
0.007(4) \\
0.05(1) \\
0.79(3) \\
0.22(4) \\
2.49(4) \\
0.091(2) \\
806(16) \\
0.56(2) \\
0.07(2) \\
3.58(7) \\
72.1(9) \\
2.18(4) \\
27.9(4)\end{array}$ \\
\hline
\end{tabular}

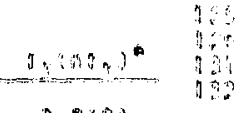

D. Ba?

का in?

a. 202

$20.0 \times 91$

10020453

76.312.5)

1.3123

6. 9123

$689420 \%$

$93(9)$

$21(1)$

98(4)

$5.5(0)$

$3.4(5)$

$478(25)$

$46(2)$

$4.0(2)$

$11.7(5)$

$73(1)$

$1612(35)$

$0.26(5)$

$10.5(8)$

45(3)

$51(3)$

$4.7(4)$

$6.0(4)$

0.3 (1)

8.5(5)

1.9(1)

$0.23(4)$

25(1)

$48(2)$

\begin{tabular}{|c|c|}
\hline \multicolumn{2}{|l|}{$132 \mathrm{Co}(0.47 \mathrm{~d})$} \\
\hline$E_{Y}\left(\Delta E_{Y}\right)$ & $I_{Y}\left(\Delta I_{Y}\right)$ \\
\hline $\begin{array}{l}363.34(5) \\
464.466(25) \\
505.77(3) \\
567.16(1) \\
630.21(1) \\
667.726(5) \\
687.74(17) \\
772.61(1) \\
1031.66(1) \\
1135.010(25) \\
1297.92(3) \\
1317.928(12) \\
1985.638(5)\end{array}$ & $\begin{array}{c}0.71(4) \\
16.0(2) \\
5.5(2) \\
2.2(1) \\
8.2(4) \\
1000(5) \\
0.02(1) \\
0.64(1) \\
1.43(4) \\
4.81(6) \\
0.69(2) \\
5.75(15) \\
0.82(12)\end{array}$ \\
\hline
\end{tabular}




\begin{tabular}{|c|c|}
\hline$\therefore=$ & 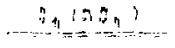 \\
\hline 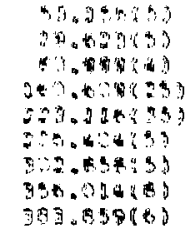 & 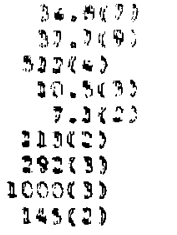 \\
\hline $13+6=12.0825$ & \\
\hline$E,\left(\in E_{Y}\right)$ & $I_{\gamma}\left(8 I_{Y}\right)$ \\
\hline $\begin{array}{l}242.90(5) \\
3: 6.46(10) \\
475.36(5) \\
563.27(5) \\
569.30(3) \\
604.68(2) \\
795.78(2) \\
801.86(3) \\
847.0(2) \\
1038.53(5) \\
1167.89(6) \\
1365.17(10)\end{array}$ & $\begin{array}{l}0.021(1) \\
0.144(6) \\
1.47(4) \\
8.38(5) \\
15.4(1) \\
97.6(3) \\
85.4(4) \\
8.73(4) \\
0.0003(1) \\
1.00(2) \\
1.81(3) \\
3.04(4)\end{array}$ \\
\hline
\end{tabular}

$1: 9 \mathrm{Gd}(9.4 d)$

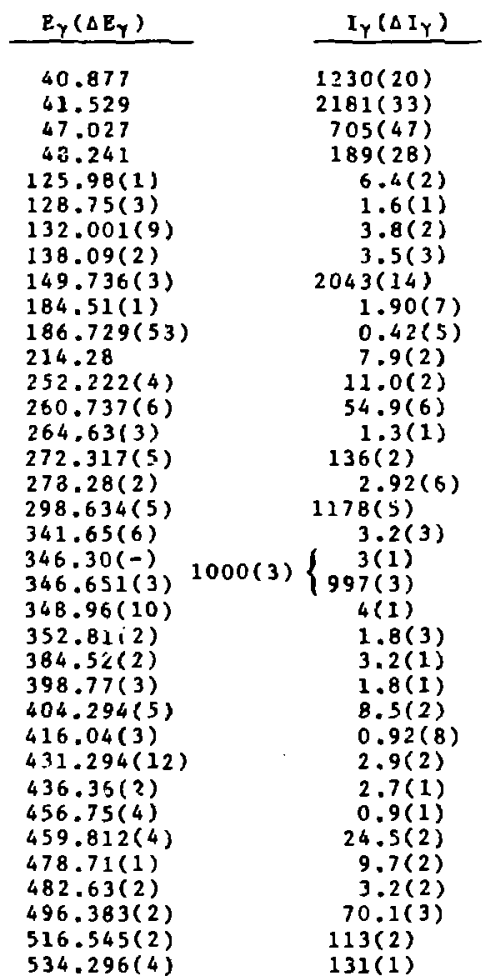

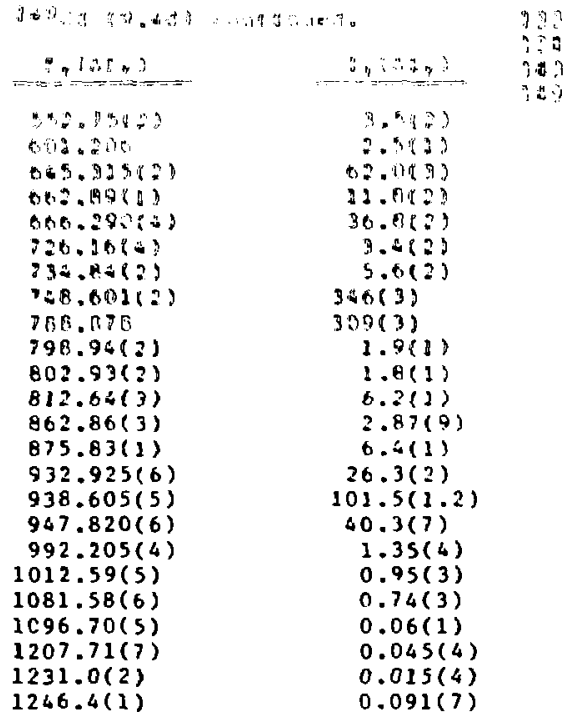

$143 \mathrm{Ce}(33.0 \mathrm{~h})$

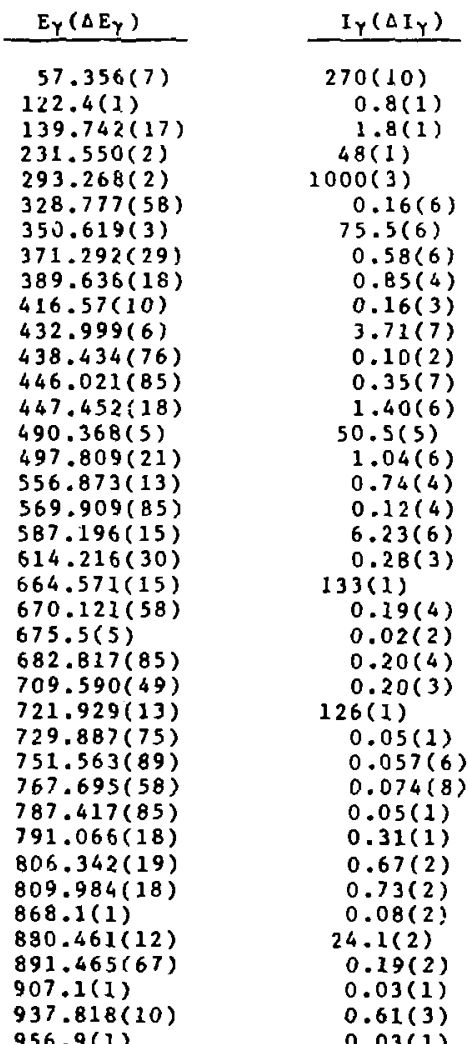




\begin{tabular}{|c|c|}
\hline 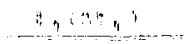 & $\therefore 74597$ \\
\hline 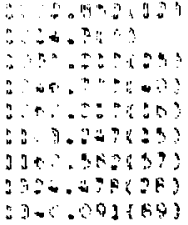 & $\begin{array}{l}3.70(2) \\
0.0382) \\
0.0729 \\
0.20(2) \\
0.03139 \\
9.3(2) \\
0.50(3) \\
0.037(1) \\
0.07293)\end{array}$ \\
\hline
\end{tabular}

:SEE (3Sy)

\begin{tabular}{|c|c|}
\hline$E_{Y}\left(\leq E_{Y}\right)$ & $I_{\gamma}\left(\Delta I_{\gamma}\right)$ \\
\hline $3: 0.721(25)$ & $1.12(9)$ \\
\hline $372.728(25)$ & $2.49(9)$ \\
\hline $377.72 \mathrm{~B}(27)$ & $1.18(8)$ \\
\hline $38: .990(26)$ & $1.17(8)$ \\
\hline $402.152(12)$ & $8.12(8)$ \\
\hline $403.36(10)$ & $2.5(1)$ \\
\hline $406.518(50)$ & $1.46(15)$ \\
\hline $420.55(22)$ & $0.14(6)$ \\
\hline $439.401(15)$ & $837(17)$ \\
\hline $448.789(12)$ & $2.7(1)$ \\
\hline $453.378(99)$ & $0.27(5)$ \\
\hline $458.363(61)$ & $0.46(5)$ \\
\hline $461.761(i 5)$ & $8.6(2)$ \\
\hline $464.114(72)$ & $4.81(8)$ \\
\hline $474.498(25)$ & $1.51(7)$ \\
\hline $476.89(13)$ & $0.19(5)$ \\
\hline $485.931(20)$ & $1.72(7$ \\
\hline $505.521(25)$ & $50(1)$ \\
\hline $509.943(4 B)$ & $1.3(1)$ \\
\hline $515.192(5)$ & $10.3(2)$ \\
\hline $520.085(19)$ & $4.8(1)$ \\
\hline $540.545(59)$ & $0.90(7)$ \\
\hline $542.972(25)$ & $1.40(7)$ \\
\hline $553.198(97)$ & $0.34(7)$ \\
\hline $571.259(15)$ & $4.3(1)$ \\
\hline $575.514(75)$ & $0.32(8)$ \\
\hline $584.274(12)$ & $548(15)$ \\
\hline $590.71(11)$ & $0.33(5)$ \\
\hline $596.529(38)$ & $0.77(7)$ \\
\hline $607.324(29)$ & $1.74(5)$ \\
\hline $612.693(28)$ & $0.97(6)$ \\
\hline $615.165(33)$ & $0.84(4)$ \\
\hline $625.568(20)$ & $3.23(7)$ \\
\hline $637.826(24)$ & $0.15(7)$ \\
\hline $658.280(55)$ & $0.55(5)$ \\
\hline $662.6 C(15)$ & $0.16(4)$ \\
\hline $667.050(25)$ & $2.7(1)$ \\
\hline $675.856(25)$ & $5.3(1)$ \\
\hline $699.5(3)$ & $0.06(4)$ \\
\hline $712.205(15)$ & $11.3(3)$ \\
\hline $731.2>n(24)$ & $3.5(1)$ \\
\hline $737.455(15)$ & $100(2)$ \\
\hline $741.467(17)$ & $8.9(1)$ \\
\hline $748.057(12)$ & $54(1)$ \\
\hline $749.797(28)$ & $7.0(1)$ \\
\hline $751.068(14)$ & $22.3(5)$ \\
\hline $756.512(20)$ & $1.18(7)$ \\
\hline $759.566(85)$ & $0.80(7)$ \\
\hline $762.034(85)$ & $0.29(5)$ \\
\hline $773.283(15)$ & $6.3(1)$ \\
\hline $816.441(75)$ & $0.51(5)$ \\
\hline $\begin{array}{l}828.562(14) \\
830.816(21)\end{array}$ & $\begin{array}{l}6.1(2) \\
5.54(12)\end{array}$ \\
\hline & \\
\hline
\end{tabular}

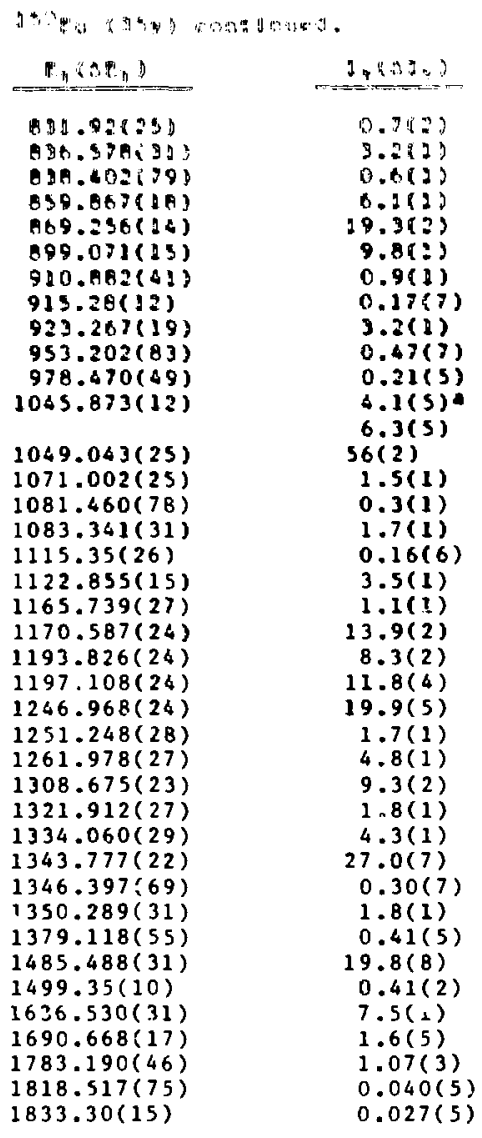

9

a Doublet.

\begin{tabular}{lc}
\hline $152 E_{U}(13.4 Y)$ & \\
$E_{Y}\left(\Delta E_{Y}\right)$ & $I_{Y}\left(\Delta I_{Y}\right)$ \\
\hline $121.783(2)$ & $1362(16)$ \\
$125.7(3)$ & $0.57(9)$ \\
$148.013(17)$ & $1.9(4)$ \\
$172.1(4)$ & $0.02(1)$ \\
$192.596(40)$ & $0.33(1)$ \\
$202.88(16)$ & $0.18(9)$ \\
$207.71(15)$ & $0.21(6)$ \\
$209.49(19)$ & $0.21(6)$ \\
$212.569(15)$ & $0.94(3)$ \\
$237.284(63)$ & $0.45(4)$ \\
$244.692(2)$ & $359(6)$ \\
$251.628(10)$ & $3.0(1)$ \\
$269.862(58)$ & $0.39(4)$ \\
$271.135(8)$ & $3.5(1)$ \\
$275.452(15)$ & $1.61(5)$ \\
$285.978(35)$ & $0.53(5)$ \\
$295.939(8)$ & $21.1(5)$ \\
$315.173(17)$ & $2.43(6)$ \\
$316.2(2)$ & $0.10(6)$ \\
$320.03(15)$ & $0.08(3)$ \\
&
\end{tabular}




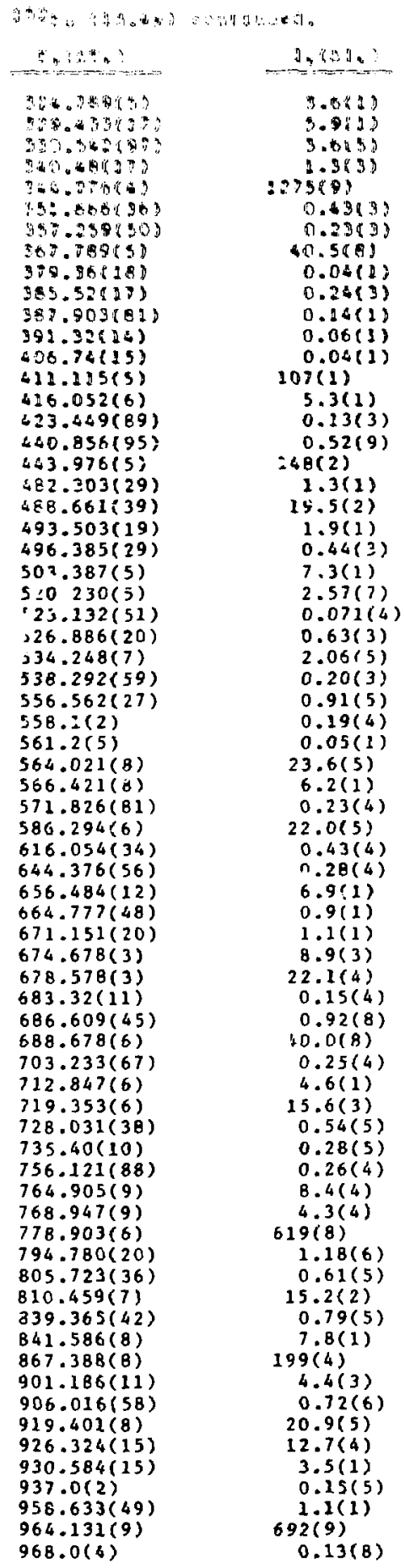

\begin{tabular}{|c|c|}
\hline $4 n^{n}, 7$ & $3, x .11,3$ \\
\hline 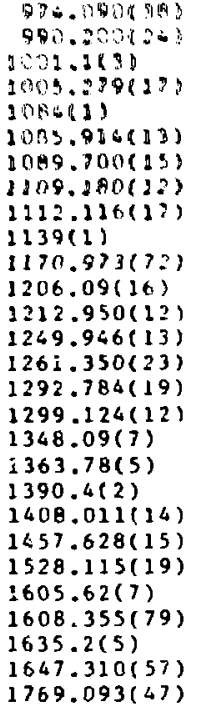 & 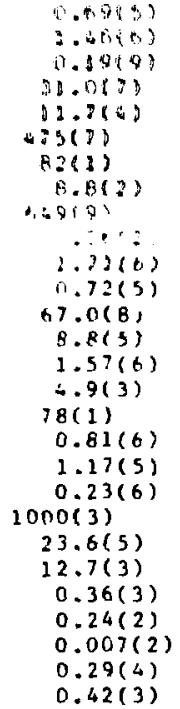 \\
\hline
\end{tabular}

$154 \mathrm{Eu}^{\dagger}(E .2 \mathrm{y})$

\begin{tabular}{l}
$E_{Y}\left(\Delta E_{Y}\right)$ \\
\hline $123.14(4)$ \\
$188.22(4)$ \\
$248.04(4)$ \\
$401.30(5)$ \\
$444.40(5)$ \\
$478.26(5)$ \\
$557.56(5)$ \\
$582.00(5)$ \\
$591.75(4)$ \\
$625.23(5)$ \\
$676.60(5)$ \\
$692.42(4)$ \\
$715.77(5)$ \\
$723.31(4)$ \\
$756.88(5)$ \\
$815.57(5)$ \\
$845.41(5)$ \\
$850.66(5)$ \\
$873.21(5)$ \\
$892.75(5)$ \\
$904.07(5)$ \\
$996.35(4)$ \\
$1004.79(4)$ \\
$1118.53(6)$ \\
$1128.43(6)$ \\
$1140.93(7)$ \\
$1188.60(10)$ \\
$1241.62(9)$ \\
$1246.63(9)$ \\
$1274.42(7)$ \\
$1493.64(8)$ \\
$1537.84(5)$ \\
$1596.52(7)$ \\
\\
\hline
\end{tabular}




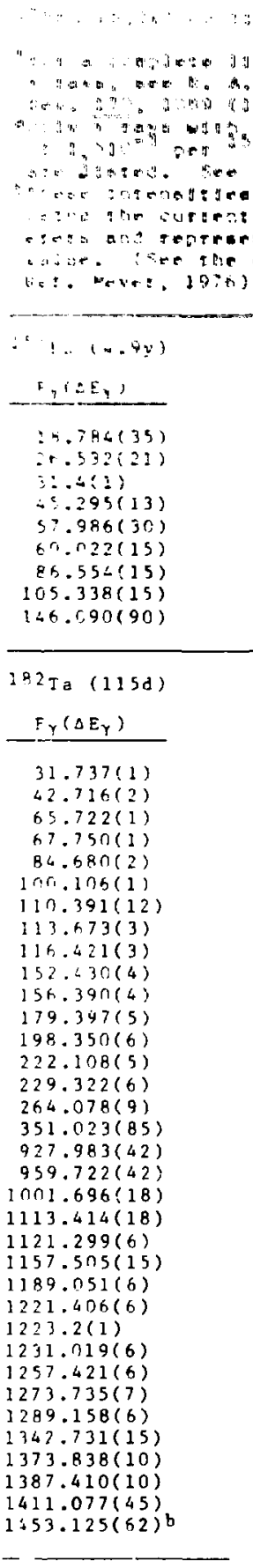

$\frac{I_{Y}\left(\Delta I_{Y}\right)}{2.4(6)}$
$15.4(6)$
$0.35(7)$
$63(3)$
$3.3(2)$
$53.9(6)$
$1496(30)$
$1000(20)$
$2.5(1)$

\begin{tabular}{c}
$I_{Y}\left(\Delta I_{Y}\right)$ \\
\hline $27.5(6)$ \\
$8.6(7)$ \\
$87.5(17)$ \\
$1310(100)$ \\
$71.9(14)$ \\
$404(5)$ \\
$3.0(2)$ \\
$53.4(5)$ \\
$12.6(2)$ \\
$199.5(1.8)$ \\
$75.9(1.0)$ \\
$88.2(1.0)$ \\
$41.9(9)$ \\
$216(3)$ \\
$103.9(1.8)$ \\
$102.6(1.8)$ \\
$0.34(8)$ \\
$17.3(3)$ \\
$9.8(3)$ \\
$58.7(6)$ \\
$13.2(3)$ \\
$1000(3)$ \\
$29.2(3)$ \\
$471(8)$ \\
$778(13)$ \\
$3(1)$ \\
$331(5)$ \\
$43.6(0)$ \\
$19.5(3)$ \\
$42.9(8)$ \\
$7.4(1)$ \\
$6.8(1)$ \\
$2.7(1)$ \\
$1.17(4)$ \\
$1.23(8) b$ \\
\end{tabular}

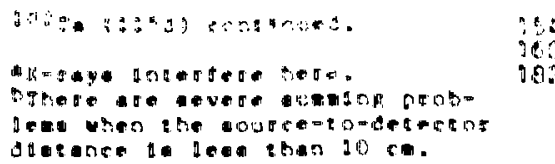

$\begin{array}{ll}87.73 & 0.03(2) \\ 99.293(2)(98.982) & 2.8(4)^{2}\end{array}$

$I_{y}(01) b .$,

$201(:)^{d}$

$\left\{\begin{array}{l}(98.982) \\ (99.289) 77.7(4)\end{array}\right.$

$0.77(5)$

$333(3)$

$1000(3)$

0.0416

$1.7 \cup(7)$

$1.66(8)$

$6.49(7)$

$5.59(8)$

$440(2)$

$0.68(8)$

$0.15(3)$

$0.58(7)$

$48.7(4)$

$4.1(2)$

$0.15(5)$

$0.11(5)$

$0.03(2)$

$0.14(5)$

$169.4(9)$

$27.7(2)$

$3.0(1)$

$228(1)$

$96.8(4)$

$0.2(1)$

$235(1)$

$7.8(1)$

$(0.2)$

935(3)

$220(1)$

128 (1)

$0.63(3)$

0.027 (15)

60.001

$57.2(3)$

$1.17(3)$

$0.21(2)$

$1.35(5)$

$0.0006(4)$

$0.008(4)$

$1.36(3)$

$0.074(9)$

$0.015(9)$

$30.9(2)$

$0.66(4)$

$0.0012(9)$

$0.40(1)$

$0.015(4)$

$1.61(2)$

$0.19(1)$

$<0.0004$

$0.008(2)$

$0.0068(15)$

$4.54(6)$

$0.039(2)$ 


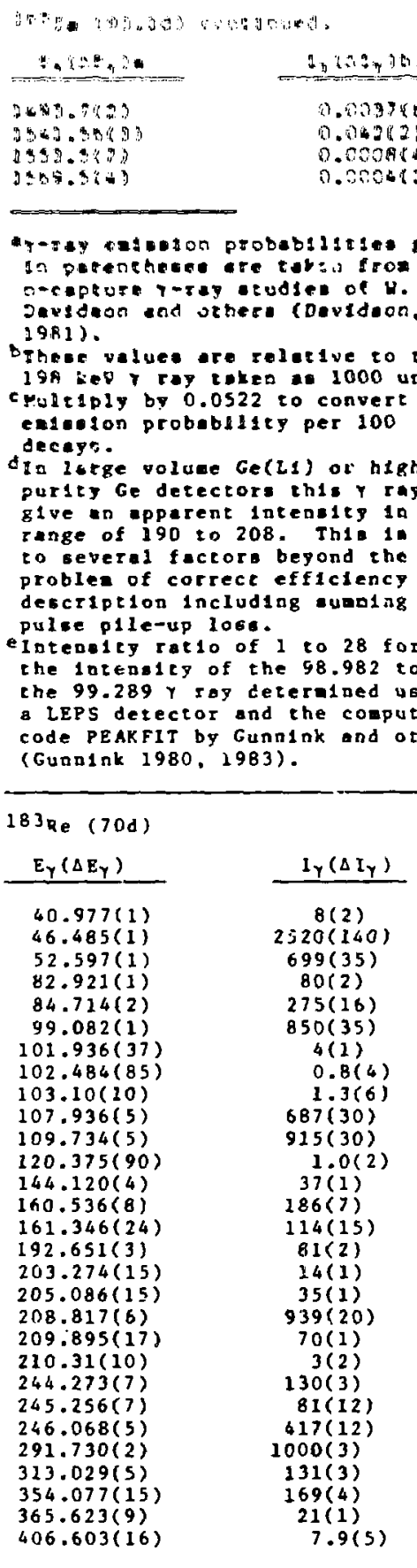

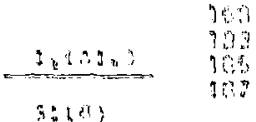

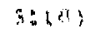

$+7.9(2)$

6. 30.7?

$51.217 ?$

$20008)$

$20.000430)$

$509(2)$

$0.00(3)$

$0.45(2)$

$0.005(4)$

$B 16(i)$

$817(3)$

$6.2(2)$

\section{$187 \mathrm{~W}(23.9 \mathrm{~h})$}

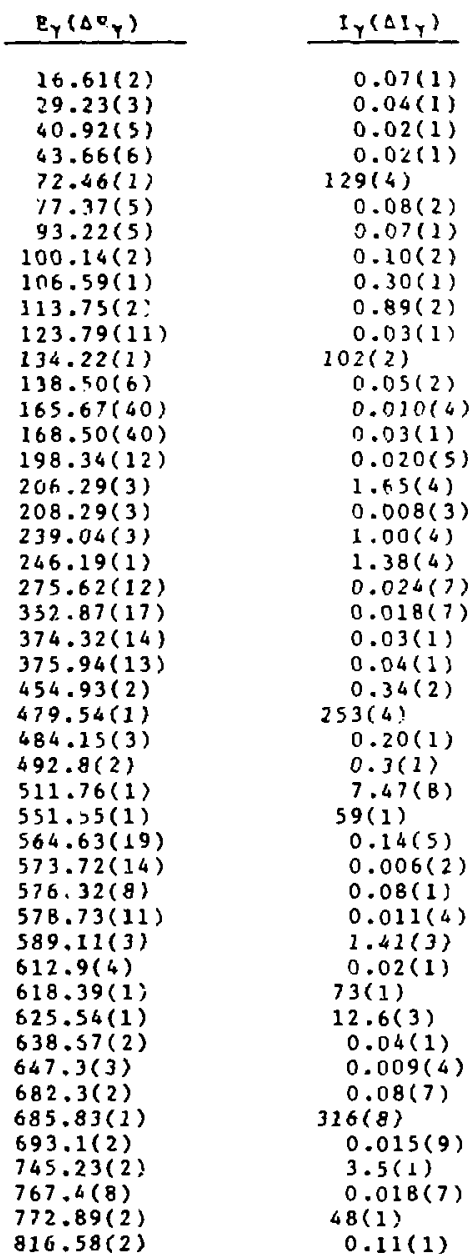

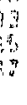




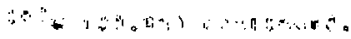

\begin{tabular}{|c|c|}
\hline$\because 405,1$ & $\therefore 6(5: 4)$ \\
\hline 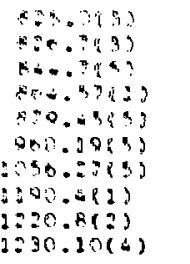 & $\begin{array}{l}0.09(4) \\
0.0027(4) \\
0.033(1) \\
3.9(2) \\
3.04(3) \\
0.025(2) \\
0.0026(7) \\
0.0025(3) \\
0.0020(6) \\
0.0025(2)\end{array}$ \\
\hline
\end{tabular}

\section{DISCLAINER}

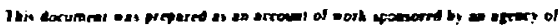

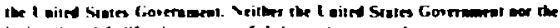

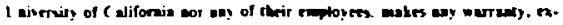

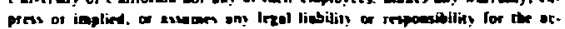

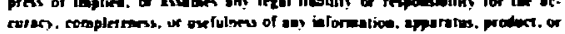

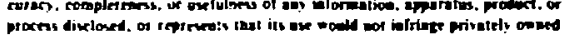

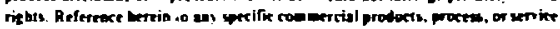

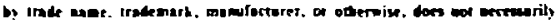

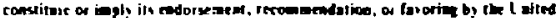

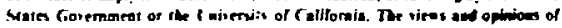

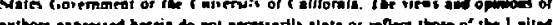

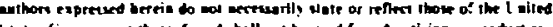

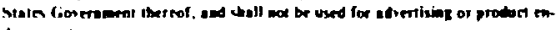
dorement putpoun. 